\title{
RegCM3 regional climatologies for South America using reanalysis and ECHAM global model driving fields
}

\author{
Anji Seth · Sara A. Rauscher · Suzana J. Camargo • \\ Jian-Hua Qian · J. S. Pal
}

Received: 13 March 2006/ Accepted: 24 August 2006/ Published online: 6 October 2006

(C) Springer-Verlag 2006

\begin{abstract}
To enable downscaling of seasonal prediction and climate change scenarios, long-term baseline regional climatologies which employ global model forcing are needed for South America. As a first step in this process, this work examines climatological integrations with a regional climate model using a continental scale domain nested in both reanalysis data and multiple realizations of an atmospheric general circulation model (GCM). The analysis presents an evaluation of the nested model simulated large scale circulation, mean annual cycle and interannual variability which is compared against observational estimates and also with the driving GCM for the Northeast, Amazon, Monsoon and Southeast regions of South America. Results indicate that the regional climate model simulates the annual cycle of precipitation well in the Northeast region and Monsoon regions; it exhibits a dry bias during winter (July-September) in the Southeast, and simulates a semi-annual cycle with a dry bias in summer (December-February) in the Amazon region. There is little difference in the
\end{abstract}

\section{A. Seth - S. A. Rauscher . S. J. Camargo .}

J.-H. Qian

International Research Institute for Climate Prediction, Columbia University, 61 Route 9W, Monell Building,

Palisades, NY 10964, USA

e-mail: rauscher@iri.columbia.edu

\author{
A. Seth (ه) \\ Department of Geography, University of Connecticut, \\ Storrs, CT, USA \\ e-mail: anji.seth@uconn.edu
}

S. A. Rauscher · J. S. Pal

Earth Systems Physics, International Center

for Theoretical Physics, Trieste, Italy annual cycle between the GCM and renalyses driven simulations, however, substantial differences are seen in the interannual variability. Despite the biases in the annual cycle, the regional model captures much of the interannual variability observed in the Northeast, Southeast and Amazon regions. In the Monsoon region, where remote influences are weak, the regional model improves upon the GCM, though neither show substantial predictability. We conclude that in regions where remote influences are strong and the global model performs well it is difficult for the regional model to improve the large scale climatological features, indeed the regional model may degrade the simulation. Where remote forcing is weak and local processes dominate, there is some potential for the regional model to add value. This, however, will require improvments in physical parameterizations for high resolution tropical simulations.

\section{Introduction}

\subsection{Motivation}

Regional climate models have been used in numerous studies for two primary purposes: (1) predictability studies or dynamical downscaling of low resolution global climate scenarios for climate change and seasonal prediction, and (2) process studies or the study of regional processes, mechanisms and variability that are currently unresolved in global models and reanalysis products. While numerous studies have focused on climate change scenarios for mid-latitudes (Giorgi et al. 1994; Mearns et al. 1995; Leung et al. 2004; 
McGregor and Walsh 1994; Christensen et al. 1998; Pal et al. 2004), relatively few have examined equatorial regions. Those that have, have emphasized seasonal prediction (Sun et al. 2005, 2006). Further, nearly all the discussion related to technical issues involved in downscaling, e.g. nudging large scales (von Storch et al. 2000; Miguez-Macho et al. 2004; Castro et al. 2005) has been in the context of mid-latitudes. A recent review of regional climate modeling research, Wang et al. (2004), which discussed both downscaling and process studies, also demonstrated that few have focused on tropical regions (Eltahir and Bras 1993, 1994; Indeje et al. 2001; Nobre et al. 2001; Rojas and Seth 2003; Fu 2003).

Because global climate models exhibit substantial predictability but also large errors in tropical regions, there is much potential and yet great challenge for regional climate models employing equatorial domains. Meanwhile it has been suggested that regional models may be excellent tools for examining climate variability and change in such regions (Huntingford and Gash 2005; Pal et al. 2006). The purpose of this paper is to draw attention to climate downscaling issues in equatorial regions, where few climate change scenarios have been performed and where seasonal prediction has potential benefit. Our specific focus is South America and its continental scale monsoon system, for which a multi-decade, ensemble climatology has been performed using a regional climate model nested in both reanalysis and GCM simulations. This analysis illustrates both the opportunities and concerns specific to downscaling in low latitude regions.

\subsection{Process studies}

Toward this purpose we first review how regional climate models have been used in process studies in the South American region. A number of process studies have been conducted which employ the increased resolution of regional models to examine structures and mechanisms that are not well resolved in global models. Berbery and Collini (2000) compiled 2-day Eta model forecasts for South America to characterize the mesoscale circulation and moisture flux associated with spring time precipitation in southeastern South America. Although the simulations showed deficient rainfall in tropical Brazil, November rainfall was simulated well in the subtropical and extratropical regions. The Eta model also was able to simulate the low level jet east of the Andes and suggested its important effect on moisture transport from the Amazon basin to the southeast region. Saulo et al. (2000) characterized the low level jet in the operational Eta model forecasts performed at the Brazilian Center for Weather Forecasts and Climate Studies (Centro de Previsão de Tempo e Estudos Climáticos, CPTEC). These process studies have suggested that moisture flux convergence in the Del Plata basin is associated with northerly transport due to the low level jet. They also have provided insight into the diurnal cycle of the mesoscale circulations and their vertical structure. However, these studies are based on short term forecasts, and are not designed to provide insight on issues related to predictability or downscaling on seasonal and longer time scales.

\subsection{Predictability studies}

Predictability on seasonal and interannual timescales is an important concern for the South American continent. El Niño-Southern Oscillation (ENSO) has substantial influence over the tropical and subtropical regions, with dry (wet) conditions in the Amazon and Northeast Brazil and wet (dry) conditions in southeastern South America during warm (cold) events (Ropelewski and Halpert 1987; Nogués-Paegle and Mo 1997). The large interannual variability observed in the Northeast is related to the Pacific forcing, which shifts the Walker circulation eastward resulting in enhanced subsidence in the Amazon and Northeast Brazil. The variability in the Northeast is also affected by more local meridional SST anomalies across the tropical Atlantic Ocean, which modify the cross equatorial pressure gradient and trade winds, and therefore the annual southward migration of the inter-tropical convergence zone (ITCZ) (Hastenrath and Heller 1977; Moura and Shukla 1981; Barros et al. 2002; C. Vera et al. submitted). Global models demonstrate good skill in predicting seasonal climate anomalies, but the spatial and temporal scale of information is insufficient for many applications. Hence, climate downscaling is being pursued for the purpose of regional seasonal prediction and has generated a number of initial results.

In order to address downscaling and predictability issues, Chou et al. (2002) performed an extended (1month) simulation with the Eta model to examine its potential for continental South America. Seth and Rojas (2003) and Rojas and Seth (2003) performed 5month regional integrations for two extreme years using both reanalysis and atmospheric general circulation model (AGCM) realizations as lateral boundary forcing with observed sea surface temperatures (SST). Testing domains which included tropical and subtropical South America, they found that errors in the low level circulation and moisture fields of the GCM significantly degraded the nested model simulation, but 
that the interannual signal was well reproduced. Menéndez et al. (2004) more recently used MM5 to simulate several warm seasons over southeastern South America using reanalysis boundary forcing. As a precursor for experimental seasonal forecasts a regional model climatology was performed for the northeast region of South America by Sun et al. (2006). The nested model was able to add some value to the global model, however, the domain in this study was limited to Northeast Brazil and other regions were not examined. Finally, Cook and Vizy (2005) and Vizy and Cook (2005) have applied the MM5 for long term simulations to examine South American climate during the last glacial maximum and employed present day reanalysed boundary forcing rather than contending with the errors inherent in this region in AGCMs. Of these, only Rojas and Seth (2003) and Sun et al. (2006) have explored the use of AGCM lateral boundary forcing in the context of downscaling. There have been no downscaling studies related to climate change for the South American region at this writing.

\subsection{Rationale}

The need for long-term simulated climatologies to provide a baseline for analysis of both seasonal prediction and climate change is apparent. Further, the value of employing multiple models was assessed in the Prediction of Regional scenarios and Uncertainties for Defining EuropeaN Climate change risks and Effects (PRUDENCE) Project (Christensen et al. 2002). The experience of PRUDENCE has influenced the methodology proposed for the North American Regional Climate Change Assessment Program (NARCCAP) (Mearns et al. 2005) which emphasizes that multiple nested model ensembles are needed to characterize the uncertainties in climate change scenarios. Such a coordinated methodology is being developed as well for South America (J. Marengo, CPTEC, personal communication). Here we present a first examination of continental-scale regional baseline climatology, where a single regional climate model is forced both by reanalysis and by multiple realizations of an AGCM.

In this work we perform and analyze a 22-year climatology for a continental scale domain over South America to enable verification of the mean climate, and its variability on interannual timescales. We also present sensitivity of the regional model results to lateral boundary forcing from large scale reanalysis and from multiple realizations of an AGCM. Examining these different boundary conditions permits evaluation of (1) best case simulations given "observed" forcing, (2) best case predictions given AGCM forcing with observed sea surface temperatures (SST), and (3) the ability to diagnose sources of error through the process of model isolation. In addition to this work, a detailed analysis of the subseasonal statistics from these simulations, including rainy season onset, demise, length, and dry spells is presented in S. Rauscher et al. (in revision).

In the next section we describe the global and regional climate models employed in this study, the data used for verification and the analysis methods. Section 3 presents the annual cycle followed by interannual variability results from the 22-year integrations. The reanalysis driven regional model is first compared against observations, then GCM and GCM-driven regional model results are discussed. Section 4 provides a discussion of the differences due to large scale forcing between the reanalysis and AGCM and possible physical processes involved including analysis of two convection schemes. Conclusions from this work are drawn in Sect. 5.

\section{Models, data, and methods}

The Regional Climate Model (RegCM) Version 3 (Pal et al. 2006) is a limited area model built around the hydrostatic dynamical component of the National Center for Atmospheric Research (NCAR)/Pennsylvania State University Mesoscale Model version 5.0 (MM5) (Grell et al. 1994). The model is compressible, based on primitive equations, and employs a terrain following $\sigma$-vertical coordinate. The model includes parameterizations of surface, boundary layer and moist processes which account for the physical exchanges between the land surface, boundary layer and free atmosphere. The model's vertical resolution is 18 levels with seven levels below $800 \mathrm{hPa}$. A vertical interpolation is performed to account for differences in vertical resolution and topography between $\mathrm{RegCM}$ and the driving fields. The limited area domain is initialized once throughout the domain and driven by atmospheric lateral boundary conditions; oceanic surface temperatures are prescribed from observations (Reynolds et al. 2002). The atmospheric lateral boundary conditions are derived from the NCEP/NCAR reanalysis (Kalnay et al. 1996), and from ensemble integrations of a global atmospheric model, the European-Hamburg (ECHAM) AGCM (Roeckner et al. 1996). The boundary forcing is interpolated horizontally and vertically to the RegCM grid and topography, and is applied at 6-h intervals.

In $\mathrm{RegCM}$, the radiation parameterization is the Community Climate Model, CCM3, radiation package 
of Kiehl et al. (1998). Exchanges of energy, moisture, and momentum between the land surface and the atmosphere are computed using the Biosphere-Atmosphere Transfer Scheme (BATS1E) land surface model (Dickinson et al. 1993). RegCM uses a medium-resolution planetary boundary scheme developed by Holtslag and Boville (1993).

New features in version 3 of RegCM include the surface flux scheme over the oceans and a subgrid explicit moisture scheme. The surface flux scheme of Zeng et al. (1998) corrects the tendency of BATS1E to overestimate latent heat flux over the oceans in both weak and strong wind conditions (J. Pal, personal communication, 2004), and in general results in decreased precipitation over the oceans. Precipitation processes are represented using a hybrid approach. Resolved (grid-scale) precipitation physics are described using the subgrid explicit moisture scheme (SUBEX) of Pal et al. (2000). SUBEX is a physically based parameterization that includes variation at the subgrid scale of clouds, cloudwater accretion, and evaporation of raindrops. Unresolved (subgrid scale) precipitation processes are represented with the cumulus parameterization scheme, which describes the effects of subgrid scale convective clouds that produce grid-scale heating and precipitation in terms of the grid scale prognostic variables (Arakawa 1993).

In these experiments, we employed two convective parameterization schemes: the Emanuel/Massachusetts Institute of Technology (MIT) scheme (Emanuel 1991; Emanuel and Zivkovic-Rothman 1999) and the mass flux scheme developed by Grell et al. (1994). In the Grell scheme, clouds are defined as two steady state circulations consisting of an updraft and a downdraft with no mixing between cloudy air and environmental air except at the cloud top and base. The scheme employs a quasi-equilibrium closure assumption (Arakawa and Schubert 1974) based on the rate of destabilization. This is a single cloud scheme with updraft and downdraft fluxes and compensating motion that determines the heating and moistening profiles.

The MIT scheme was recently added to the RegCM modeling system; it is a more physically realistic scheme. Convection is triggered when the level of neutral buoyancy is greater than the lifting condensation level (cloud base). Air is lifted between these two levels and a fraction of the condensed moisture forms precipitation while the remainder forms the cloud. The cloud mixes with the air from the environment according to a uniform spectrum of mixtures that ascend or descend to their respective levels of neutral buoyancy. In the formulation employed, the convective adjustment assumes strict equilibrium.
2.1 Regional climate model driving data

\subsubsection{Global climate model (ECHAM)}

The European Community-Hamburg (ECHAM, version 4.5) is an atmospheric GCM derived from the European Centre for Medium-Range Weather Forecasts (ECMWF) spectral prediction model (Roeckner et al. 1996). It has a hybrid sigma-pressure vertical coordinate. In the ensemble members used in these experiments, ECHAM has a horizontal T42 spectral resolution $\left(2.8^{\circ}\right.$ latitude-longitude $)$ and has 19 vertical levels, with the top extending to $10 \mathrm{hPa}$. The model's prognostic variables are vorticity, divergence, surface pressure, temperature, specific humidity, and the mixing ratio of total cloud water. The mass flux scheme of Tiedtke (1989) is employed for both deep and shallow convection. For full details on the ECHAM model, readers may refer to Roeckner et al. (1996).

A 24-member ensemble of 50+-year integrations (1950-present) using observed monthly SST has been performed and archived at the IRI. From this ensemble, one realization was chosen based on simulation skill for the January-March seasons of 1983 and 1985 (Rauscher et al. 2006); two additional ensemble members were selected at random. Three realizations from the GCM provided lateral boundary forcing at 6$\mathrm{h}$ intervals for the 1982-2003 period to drive the regional climate model (see Table 1).

\subsubsection{Reanalysis data (NCEP/NCAR)}

Model initial and lateral boundary conditions were created with three ensemble members of ECHAM (described in the preceding section) and the NCEPNCAR Reanalysis Project (NNRP) (Kalnay et al. 1996). NNRP is derived from various data sources including rawinsondes, surface marine data, aircraft data, surface land synoptic data, satellite sounder data, special sensing microwave imager, and satellite cloud drift winds. Quality control studies are performed and the data is assimilated using a numerical prediction model. SSTs were obtained from the NOAA optimum interpolation (OI) SST analysis (Version 2) (Reynolds et al. 2002). In many regions where observations are sparse, particularly in the tropics, the NNRP dataset is more model dependent.

\subsection{Methods}

RegCM experiments were performed for South America using a continental scale domain with $80 \mathrm{~km}$ horizontal resolution and $111 \times 138$ grid points $($ see 
Table 1 Numerical experiments performed and discussed in the results

\begin{tabular}{lllll}
\hline Experiment & Convection & L.B.C. & Period & \# Realizations \\
\hline ECHAM & TIEDKE & N/A & $1950-2002$ & $24(3)$ \\
NN-RegCM & GRELL & NNRP & $1982-2002$ & 1 \\
EC-RegCM & GRELL & ECHAM & $1982-2002$ & 3 \\
NN-RegCM-EM & EMANUEL & NNRP & $1996-2002$ & 1 \\
EC-RegCM-EM & EMANUEL & ECHAM & $1996-2002$ & 3 \\
\hline
\end{tabular}

ECHAM model ensemble simulations are archived ar IRI. All regional simulations were performed for this study

Fig. 1). The control simulations, which employed the Grell convection scheme were for the period 19822003. This series of integrations included one realization using NNRP boundary conditions (hereafter, NN$\mathrm{RegCM}$ ) and three realizations using the ECHAM global model driving fields (hereafter, EC-RegCM; see Table 1). The model-output precipitation is compared with the Climate Prediction Center Merged Analysis of Precipitation (CMAP) (Xie and Arkin 1996) while the dynamical fields are compared to the NNRP.

Several regions have been defined for the analysis presented. The northern Amazon Basin $\left(5^{\circ} \mathrm{N}-\right.$ $5^{\circ} \mathrm{S}, 70^{\circ} \mathrm{W}-55^{\circ} \mathrm{W}$ ) has relatively small seasonality but some demonstrated relationship to ENSO; the Monsoon region $\left(15^{\circ} \mathrm{S}-25^{\circ} \mathrm{S}, 58^{\circ} \mathrm{W}-45^{\circ} \mathrm{W}\right)$ represents the core of the continental scale monsoon, exhibits distinct dry and wet seasons, but has very little ENSO related predictability; the Northeast $\left(2^{\circ} \mathrm{S}-12^{\circ} \mathrm{S}, 45^{\circ} \mathrm{W}-35^{\circ} \mathrm{W}\right)$ shows both substantial seasonality and relationship to

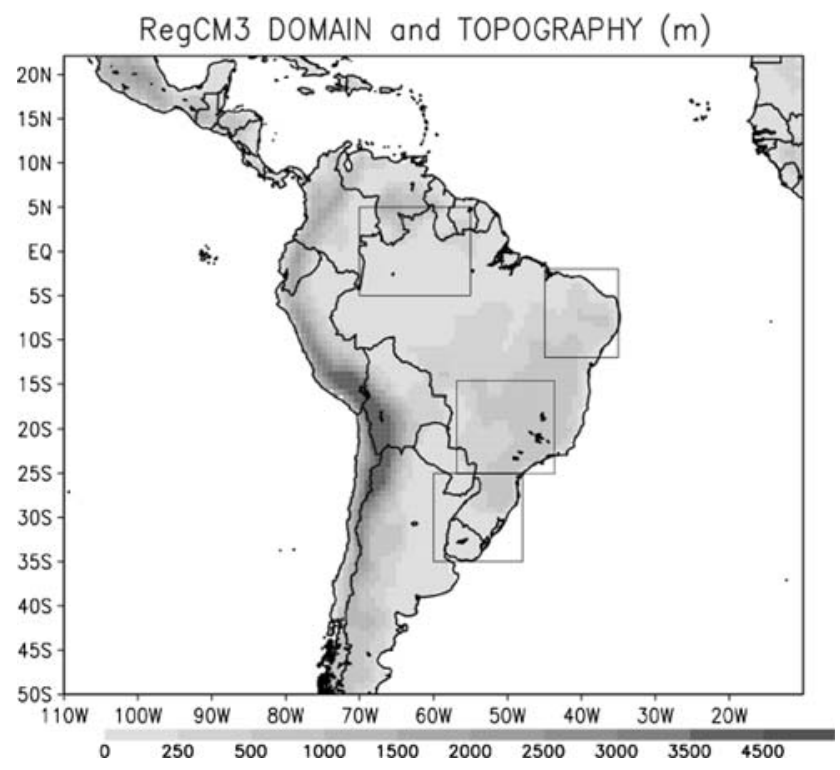

Fig. 1 RegCM3 domain used in the present study: $111 \times 138$ grid points, $80 \mathrm{KM}$ horizontal resolution. Shaded contours show topography. Boxes indicate the Amazon, Northeast, Monsoon and Southeast regions used in area average calculations discussed in the results
ENSO, and the Southeast region $\left(25^{\circ} \mathrm{S}-35^{\circ} \mathrm{S}, 60^{\circ} \mathrm{W}-\right.$ $48^{\circ} \mathrm{W}$ ) does not have strong seasonality in precipitation but does have relationship to ENSO. All regions are defined over land only.

Composite analysis is presented using the four strongest warm ENSO events (1982-1983, 1986-1987, 1991-1992, 1997-1998) and four strongest cold ENSO events (1984-1985, 1988-1989, 1998-1999, 1999-2000) during the 1982-2003 period. These years were selected based on the NOAA Climate Prediction Center's Oceanic Niño Index (ONI), which employs Niño 3.4 SST anomalies. Cold and warm episodes are defined when the threshold of $\pm 0.5^{\circ} \mathrm{C}$ is met for a minimum of five consecutive overlapping seasons.

\section{Results}

We separate the presentation of results into two parts. First, RegCM is evaluated under "perfect" forcing conditions, i.e. using reanalysis driving fields. The GCM and GCM-driven regional model results are presented as averages of the three realizations in the second part (Sect. 3.2). Note that the figures include the observations and all model results side-by-side for ease of comparison, though the discussion is separated for clarity.

\subsection{Reanalysis driven RegCM}

\subsubsection{Mean annual cycle}

We begin by examining the mean annual cycle for the 1982-2003 period. Figure 2 presents the annual cycle computed from pentad precipitation, averaged from $65^{\circ}$ to $40^{\circ} \mathrm{W}$, and plotted latitude versus time. The CMAP observations (Fig. 2a) show the rains between $5^{\circ} \mathrm{N}$ and $10^{\circ} \mathrm{N}$ in July and August. In October and November, a secondary maximum appears near $10^{\circ} \mathrm{S}$ which then proceeds to merge with the northward maximum through the early rainy season. The northward retreat of the rains begins in March. This observational estimate suggests that the rains do not proceed 


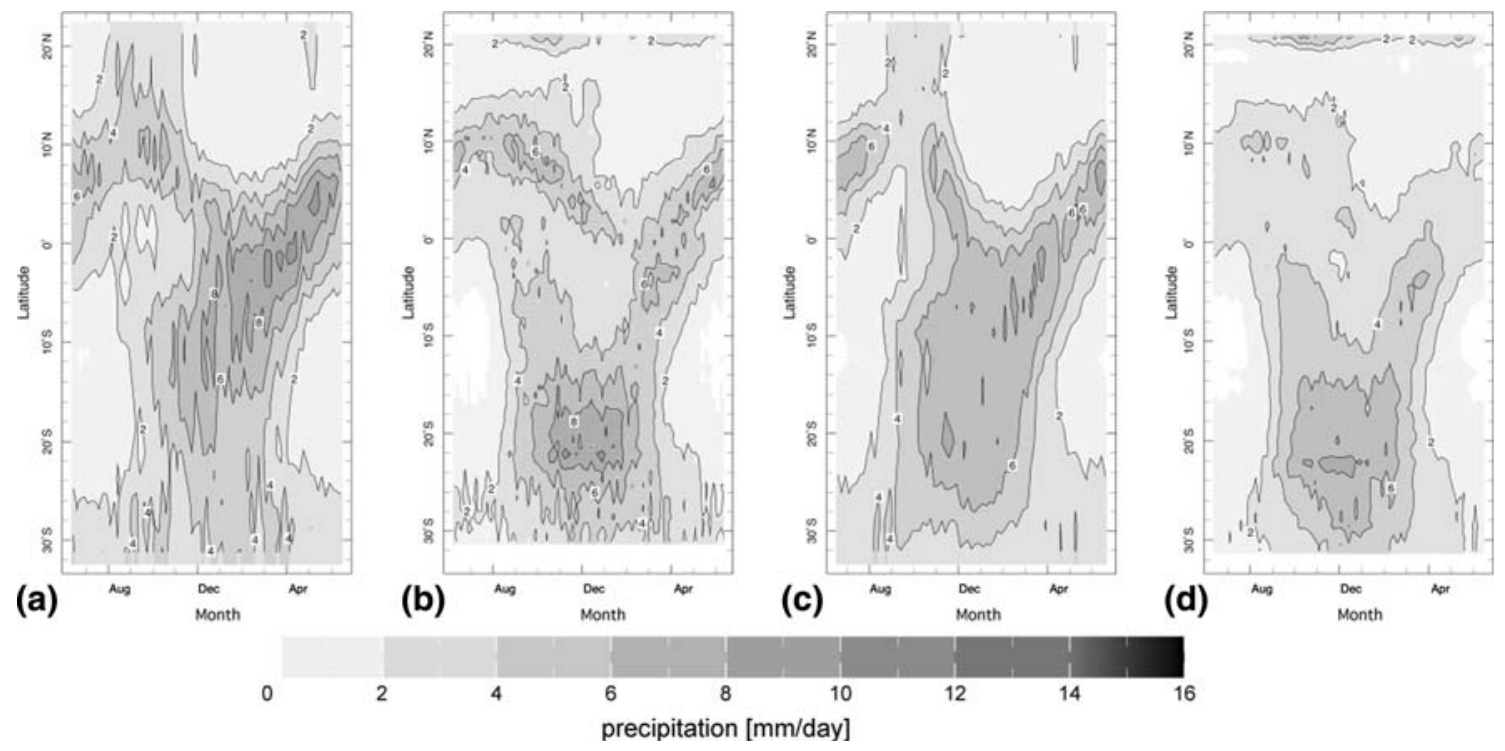

Fig. 2 1982-2003 Annual cycle of precipitation shown by latitude and pentad, averaged from $65^{\circ} \mathrm{W}$ to $40^{\circ} \mathrm{W}$ for a $\mathrm{CMAP}, \mathbf{b} \mathrm{NN}-$ RegCM, c ECHAM, and d EC-RegCM

smoothly from north to south, as suggested by the outgoing longwave radiation (OLR) analysis of Kousky (1988), but rather, there is a discontinuity, with a maximum appearing near $10^{\circ} \mathrm{S}$ in the early season and merging with the rains from the north by December. This view of the annual cycle has been noted also by B. Liebmann et al. (in review). Southward of $30^{\circ} \mathrm{S}$ frontal systems result in winter precipitation, while only warm season precipitation is seen between $5^{\circ} \mathrm{S}$ and $25^{\circ} \mathrm{S}$.

The NN-RegCM integration (Fig. 2b) captures the annual cycle, but with two deficiencies. While the model simulates the discontinuous "jump" to the south, and captures the early (October-November) and late (March-April) season rains well, the northward expansion of rains is weak, resulting in a drier than observed Amazon region during the primary rainy season (December-February). The NN-RegCM also locates the maximum rainfall farther to the south than the observations. The dry bias seen here in the Amazon region has been noted by Seth and Rojas (2003) using an earlier version of RegCM, and appears to be a common error afflicting climate models, e.g. Cavalcanti et al. (2002).

Area averaged annual cycles of precipitation are computed for the Northeast, Southeast, Amazon and Monsoon regions (Fig. 3). According to the CMAP estimate, the Northeast rainy season peaks just under $7 \mathrm{~mm}$ /day between February and May and drops to less than $2 \mathrm{~mm}$ /day between June and December (Fig. 3a). The NN-RegCM simulates a slightly reduced amplitude annual cycle and overall good timing. In the Southeast the CMAP observations describe a smaller annual cycle, ranging from $6 \mathrm{~mm} /$ day in January to just under $4 \mathrm{~mm} /$ day in July (Fig. 3b). Here the regional model simulates peak rainy season well, with a maximum of $6 \mathrm{~mm} /$ day in December and January, but is drier than observed during the rest of the year, with near $2 \mathrm{~mm} /$ day in July. Rains in the Amazon region peak during the retreat phase of the South American monsoon in April and May. CMAP estimates describe a peak near $10 \mathrm{~mm} /$ day between April and May, and a smaller ( $5 \mathrm{~mm} /$ day) secondary maximum during the onset phase in November and December (Fig. 3c). The regional model exhibits a semi-annual cycle in precipitation in the Amazon with peaks in April and September. This result highlights and re-emphasizes a common problem in the simulation of Amazon rainfall, wherein models tend to produce rainfall in response to the semiannual solar forcing in the region (Bonan et al. 2002; Marengo et al. 2003; M. Rojas et al. in preparation). Our analysis will examine these errors in some detail, as well as their influence on the Southeast and Monsoon regions. A strong annual cycle is observed in the Monsoon region with the rainy season onset in October and demise in April, with peak precipitation of $7 \mathrm{~mm} /$ day in December and January. The NN-RegCM simulation in the region shows a good amplitude with a slight early shift to the phase (Fig. 3d).

We next examine spatial patterns of precipitation and the associated low level circulation; Fig. 4 presents January-March (JFM) and July-September (JAS) seasonal mean precipitation and $850 \mathrm{hPa}$ winds. During JFM the ITCZ is approaching its southern most location and the South American monsoon related 

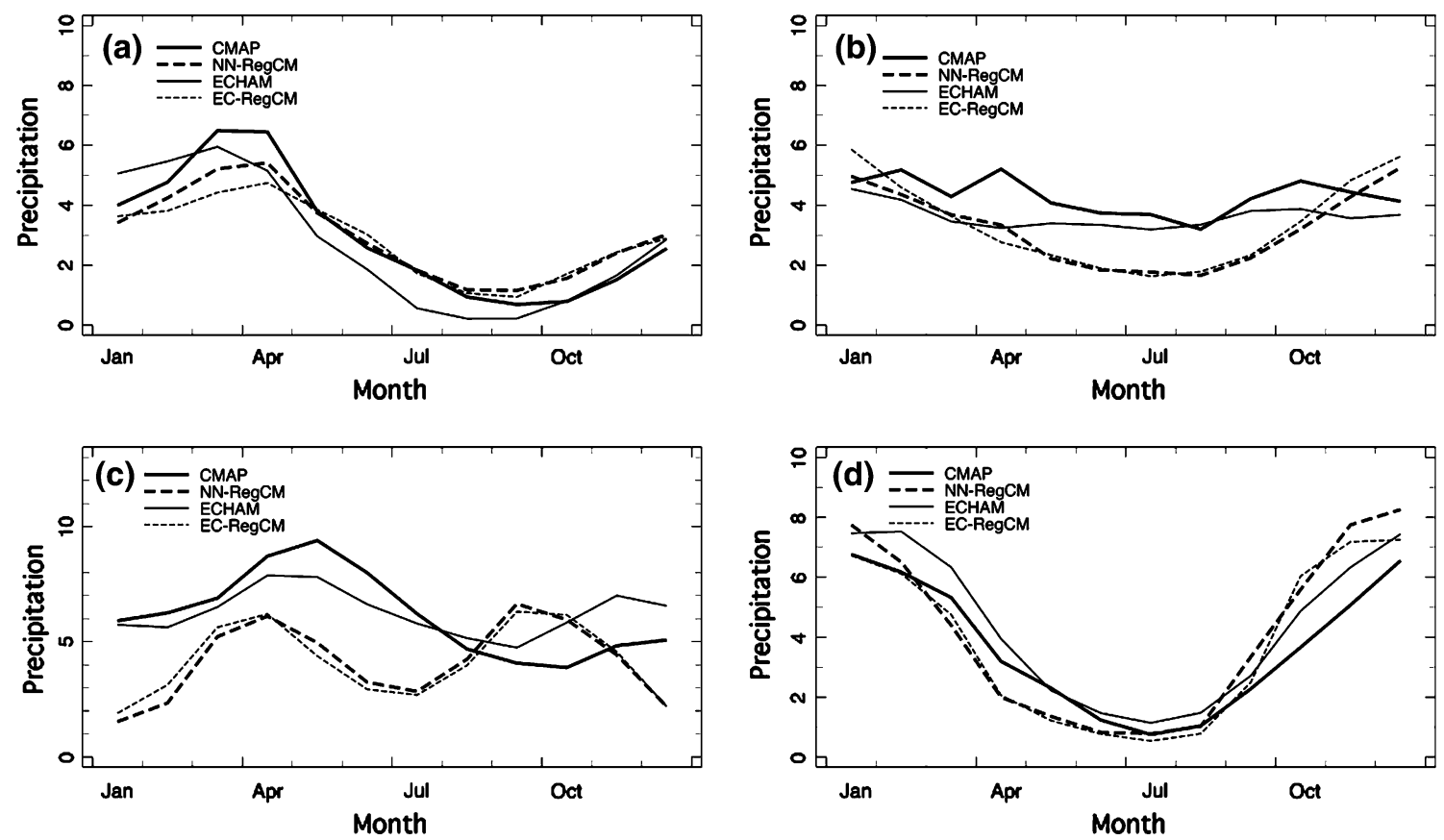

Fig. 3 1982-2003 average monthly precipitation (mm/day) for the a Northeast, b Southeast, c Amazon, and d Monsoon regions from CMAP (thick solid), ECHAM (solid), NN-RegCM (dashed), EC-RegCM (dotted)

rains are widespread (CMAP observations, Fig. 4a). Low level easterly winds transport moisture into the Amazon Basin from the Atlantic Ocean. The winds become northerly as they approach the Andes Mountains and carry moisture from the Amazon to the subtropical regions. In addition the western periphery of the anti-cyclonic flow around the South Altantic subtropical high converges with westerly subtropical jet flows to form the quasi-stationary South Atlantic Convergence Zone (SACZ) which is active during this season (Barreiro et al. 2002). During JAS the ITCZ and monsoon rainfall have retreated to the north (Fig. 4b). The South Atlantic subtropical high has retreated equatorward and frontal systems associated with baroclinic waves continue to bring precipitation to the southeastern region (Vera et al. 2002).

The NN-RegCM (Fig. 4c, d) simulates the major features of precipitation in JFM including the southward and westward enhancement of the Atlantic ITCZ, the enhancement of the SACZ, and the broad development of the continental rains. The regional model simulation shows drier than observed conditions in the northern Amazon region and wetter than observed in the region of the low level jet, east of the Andes, consistent with the results in Fig. 2. The dry bias is associated with weaker than observed easterly and northerly winds from the tropical Atlantic where the anticyclone is eastward of the observed position, resulting in weaker inflow to the continent. The model does capture the northward retreat of the monsoon. The JAS precipitation in the Southeast is weak as we saw from the regional climatology in Fig. 3. This is associated with weaker than observed northerly flow over Paraguay which provides the moisture source for precipitation systems (Vera et al. 2002).

Sea level pressure (SLP) (not shown) indicates that the RegCM3 anti-cyclone is not well formed on its northern and western flanks. This results in a broad region of diffuse flow into the continent, rather than the more focused flow around the anti-cyclone present in the reanalysis (not shown). The weaker than observed easterly trades may be related to the underestimation of precipitation in northern Amazon. Less precipitation in northern Amazon reduces atmospheric latent heating, which alters the mesoscale circulation by reducing low-level convergence toward the region, similar to what occurs in the case of the Mei-yu front in China (Qian et al. 2004). This also has implications for moisture transport into and out from the Amazon.

\subsubsection{Interannual variability}

While the annual cycle provides a critical baseline for our discussion, we are interested in the ability of the regional model to simulate interannual variability. In order to evaluate the regional model response to large scale forcing and ocean SST anomalies, precipitation time series for the Northeast (February-April, FMA) 
Fig. 4 1982-2003 seasonal mean precipitation and 850 $\mathrm{mb}$ winds for JFM (left) and JAS (right) from a, b CMAP/ NNRP, c, d NN-RegCM, e, f ECHAM, and $\mathbf{g}, \mathbf{h}$ EC$\mathrm{RegCM}$
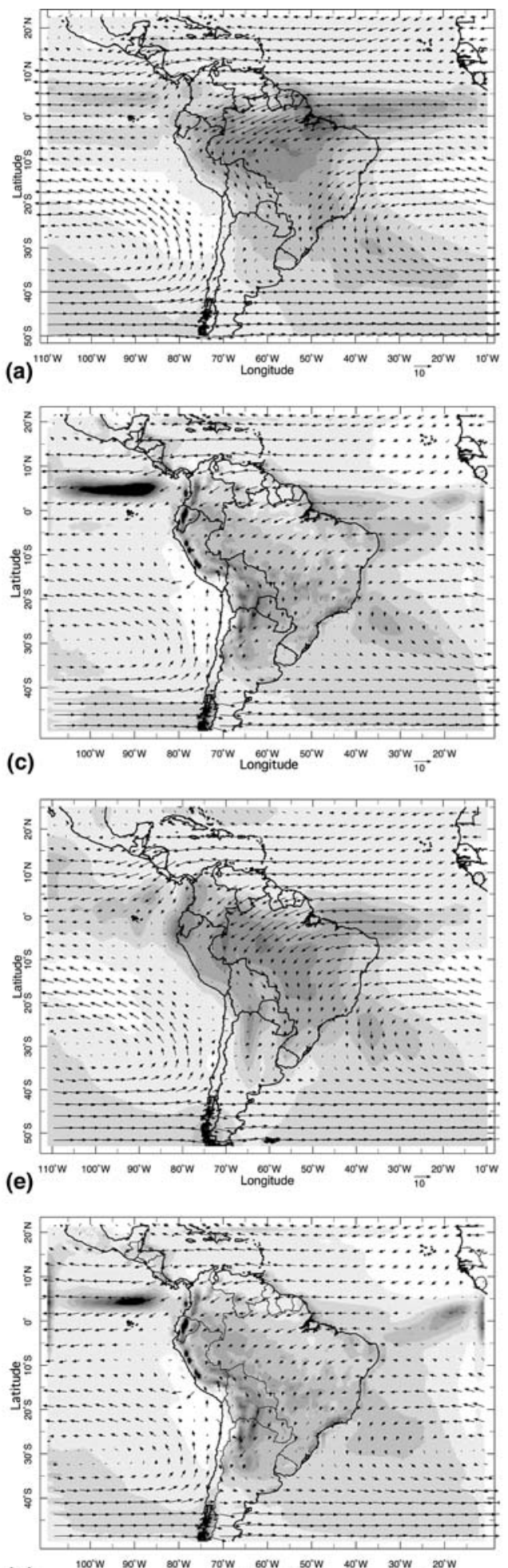

(g)

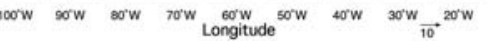

(h)
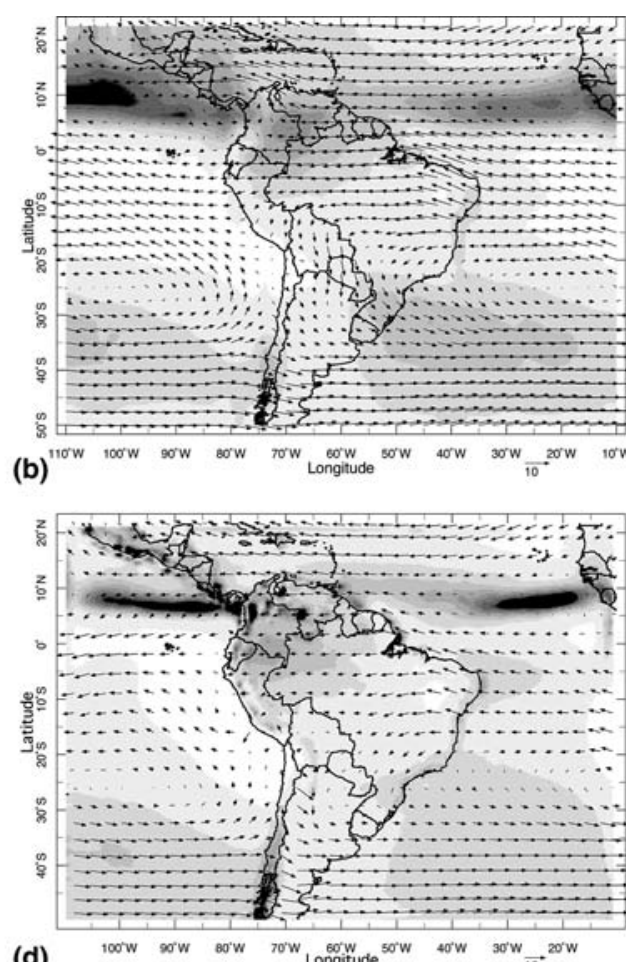

(b)

(d)
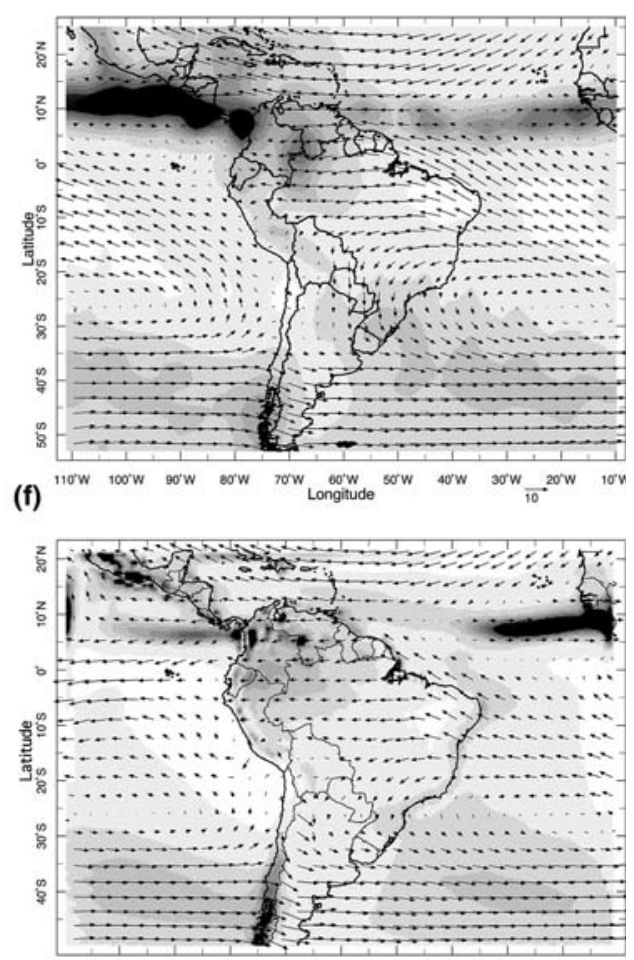

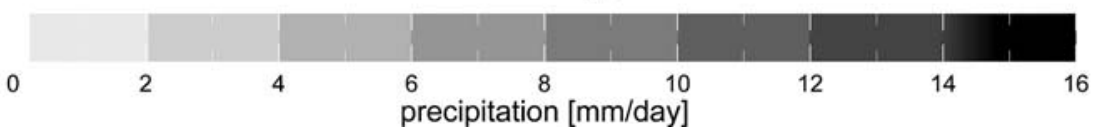

and the Southeast (OND) are correlated with sea surface temperature anomaly at each gridpoint globally for the same season. Note that the regional model only "sees" the SST within the model domain. Outside the domain the SSTs are "felt" through their influence on the atmospheric lateral boundaries. Figure 5 shows 
the correlations for the Northeast (left) and Southeast (right). The CMAP observations (Fig. 5a, b) demonstrate the well established relationships with the tropical Pacific Ocean, i.e. the Northeast rainfall is negatively correlated with El Niño and the Southeast shows a positive correlation (Ropelewski and Halpert 1987). Northeast rainfall is also related to warm anomalies in the southern tropical Atlantic and cold conditions north of the equator (Hastenrath and Heller 1977; Moura and Shukla 1981). The NN-RegCM simulation performs very well in the Northeast region, although the relationship to the southern tropical Atlantic is slightly weaker than observed (Fig. 5c). In the Southeast the model relationship to Pacific SST anomaly is approximately two-thirds of the observed signal is captured by the model (Fig. 5d). It is not immediately clear why this is so.

Area averaged seasonal precipitation anomalies for the Northeast (FMA), Southeast (OND), Amazon and
Monsoon (DJF) regions are provided in Fig. 6 and correlations between CMAP and simulated precipitation are given in Table 2. In the Northeast, the NNRegCM simulates the year-to-year variations well, although a reduced amplitude is seen in the anomalies compared with observations, particularly during the wet event of 1985 and the dry events of 1993 and 1998 (Fig. 6a, correlation $=0.64)$. The interannual variability in the Southeast is also well simulated by the NNRegCM, with the exception that the wet event in 1998 is weaker than observed (Fig. $6 \mathrm{~b}$, correlation $=0.78$ ). The Amazon region, which poses the most difficulty for the NN-RegCM, shows a reasonably good simulation of year-to-year variability (Fig. $6 c$, correlation $=0.60$ ). Also of note in the Amazon is an apparent increase in the amplitude of positive anomalies after the mid 1990s. This will be examined further in the Discussion section. Interannual variability in the Monsoon region not strongly infulenced by tropical SST anomalies
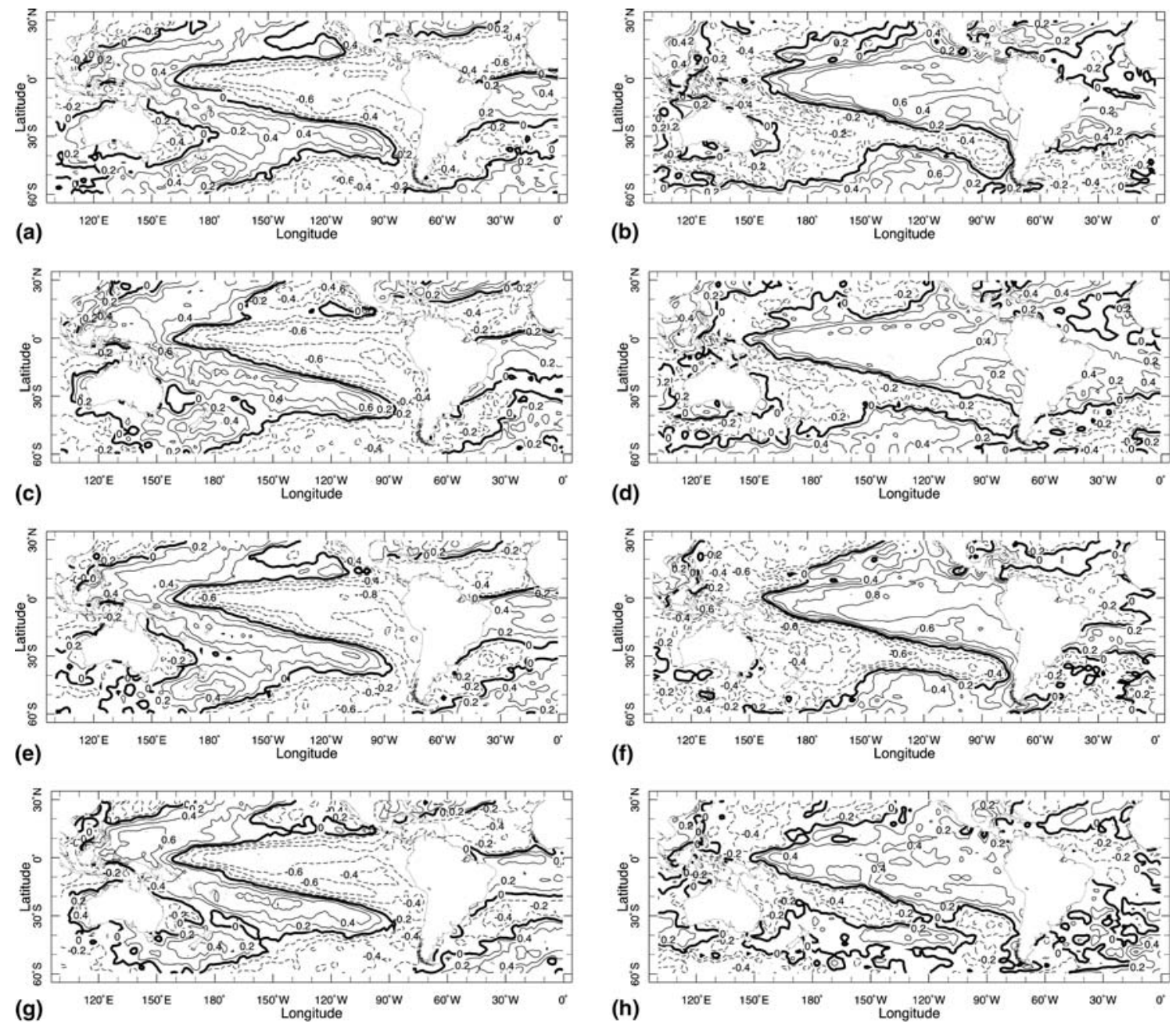

Fig. 5 1982-2003 correlations of global SST anomaly with precipitation anomaly for Northeast Brazil (left) and Southeast South America (right). a, b CMAP, c, d NN-RegCM, e, f ECHAM, and g, h EC-RegCM 

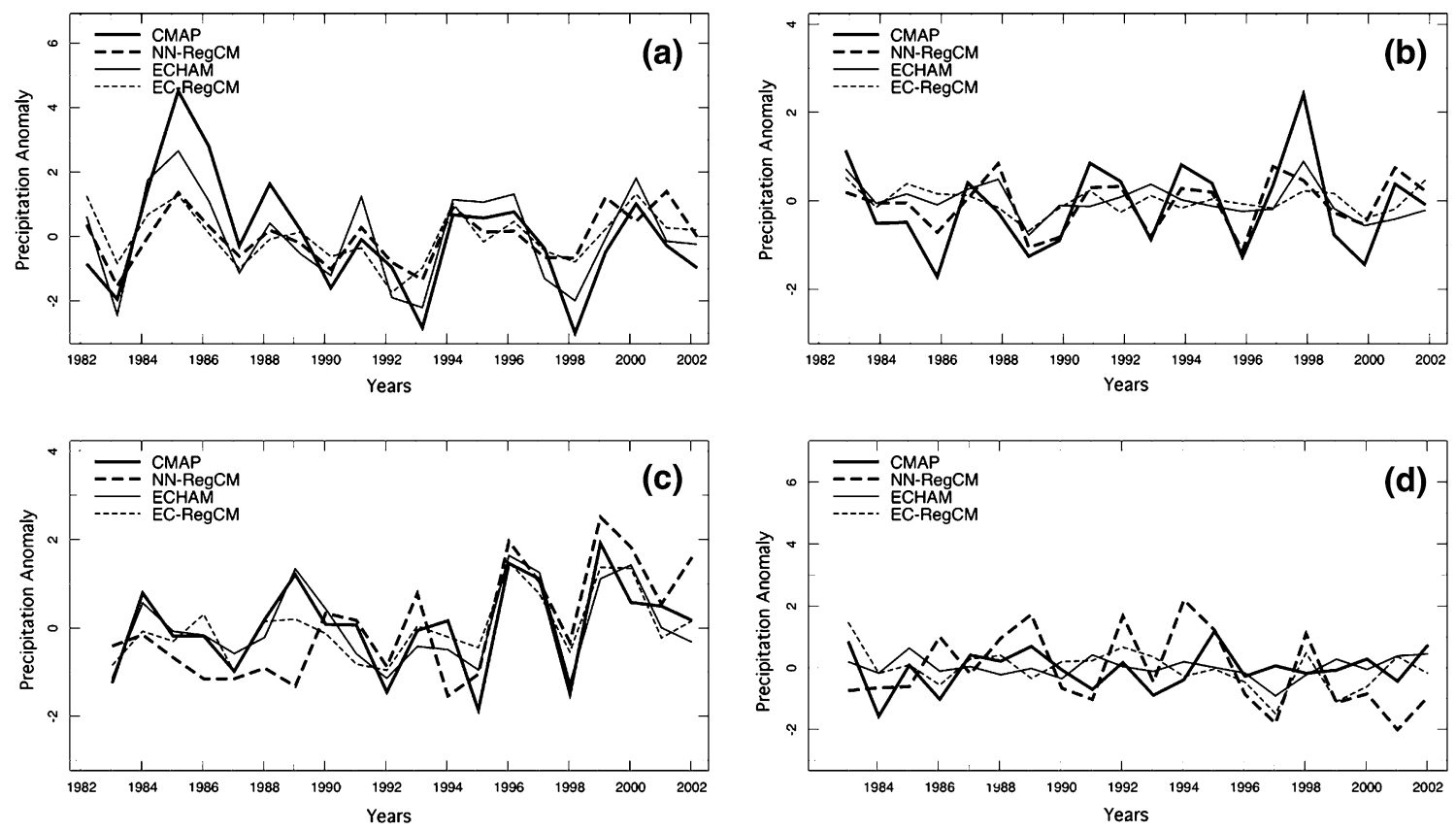

Fig. 6 1982-2003 monthly preciptition anomaly (mm/day) for the a Northeast (FMA), b Southeast (OND), c Amazon (DJF), and d Monsoon (DJF) regions from CMAP (thick solid), ECHAM (solid), NN-RegCM (dashed), EC-RegCM (dotted)

Table 2 Correlation between CMAP and simulated precipitation from each model and for each region analyzed

\begin{tabular}{llll}
\hline & NN-RegCM & ECHAM & EC-RegCM \\
\hline Northeast & 0.64 & 0.83 & 0.60 \\
Southeast & 0.78 & 0.55 & 0.30 \\
Amazon & 0.60 & 0.89 & 0.79 \\
Monsoon & 0.25 & 0.07 & 0.22 \\
\hline
\end{tabular}

(Nogués-Paegle and Mo 1997) and may be more responsive to local processes such as soil moisture or sub-tropical SST anomalies (Grimm 2003). While NNRegCM simulation of Monsoon region precipitation shows significant variability, its correlation with observed is weak (Fig. 6d, correlation $=0.25$ ).

We examine the spatial patterns of simulated precipitation anomaly response by computing composites of precipitation anomalies for warm and cold ENSO years. The JFM average precipitation anomalies for the four warmest events $(1983,1987,1992,1998)$ and coldest events $(1985,1989,1999,2000)$ during the 1982-2003 period are given in Fig. 7. CMAP observations, show the dry conditions through the northern Amazon and the Atlantic ITCZ region and wet conditions in the Pacific ITCZ and southeast South America during Pacific warm events (Fig. 7a). During cold events (Fig. 7b) the Northeast coast and Atlantic ITCZ are wet and the Pacific ITCZ and Southeast are dry.
The NN-RegCM (Fig. 7c, d) reproduces the dry conditions in the Northern Amazon and Altantic ITCZ well. Simulations of the cold event years are also capturing the wet conditions in the northern Amazon and Atlantic ITCZ. In the Southeast, the model appears to simulate a shift in the SACZ, with relatively wetter conditions during the warm events over southern Brazil and corresponding dry conditions over southeast Brazil. The opposite is seen in the NN-RegCM simulations for Pacific cold events. This is not unlike the shifting nature of the SACZ described by NoguésPaegle and Mo (1997) and Robertson and Mechoso (2000), but has not been clearly associated with ENSO (Carvalho et al. 2004) in diagnostic analysis, and is not seen in the CMAP estimates.

JFM SLP anomaly composites (Fig. 8) add further insight. The NNRP observed estimates show clearly the enhanced (reduced) subsidence over the eastern South American continent and the Altantic basin and lower (higher) than average SLP in the Pacific basin, consistent with the warm (cold) event (Fig. 8a, b). While the NN-RegCM (Fig. 8c, d) simulates these anomalies well over the ocean basins, in the interior Amazon the regional model is showing the opposite sign anomalies compared with NNRP. In reality, northern Amazon is located under the ascending branch of the Walker circulation. However, the Reg$\mathrm{CM}$ simulations underestimate the Amazon precipitation as well as the easterly trade winds from the 
Fig. 7 Composite JFM precipitation anomalies for Warm ENSO (1983, 1987, 1992, 1998) (left) and Cold ENSO (1985, 1989, 1999, 2000) (right) from a, b CMAP,, $\mathbf{d}$, NN-RegCM, e, f ECHAM, and $\mathbf{g}, \mathbf{h}$ EC$\mathrm{RegCM}$

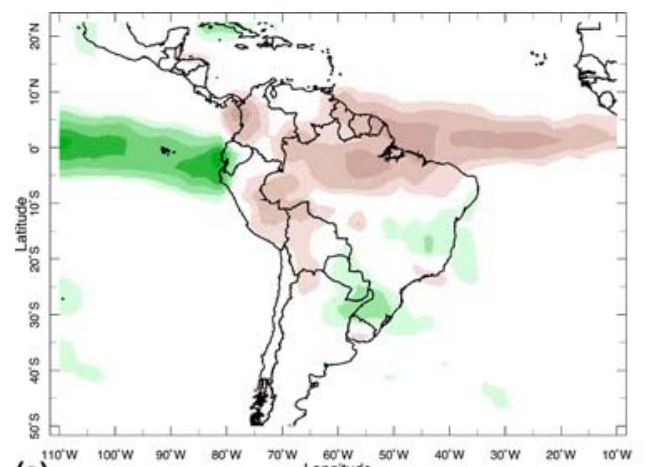

(a)
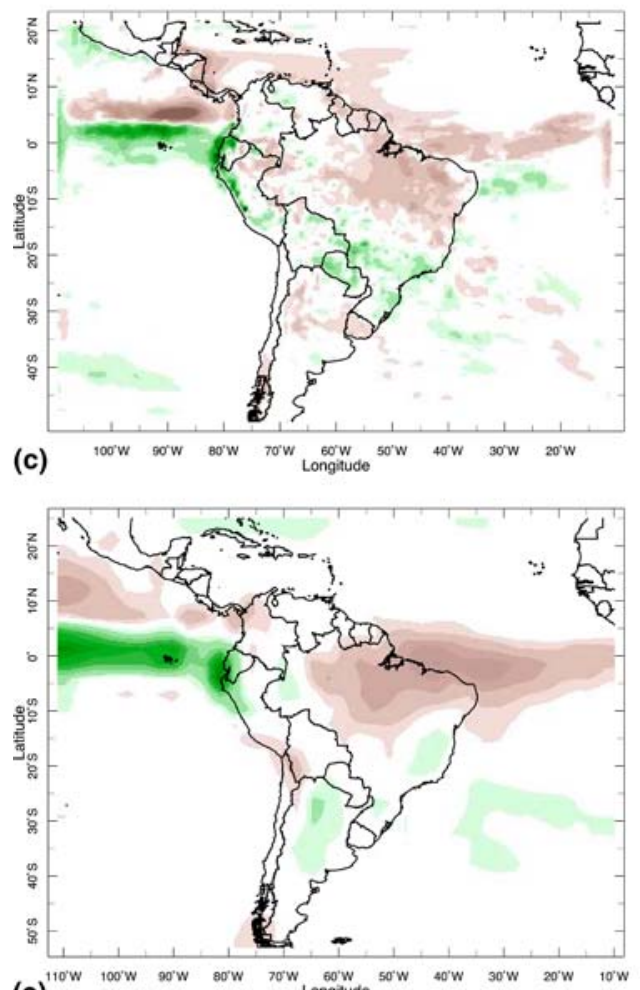

(e)
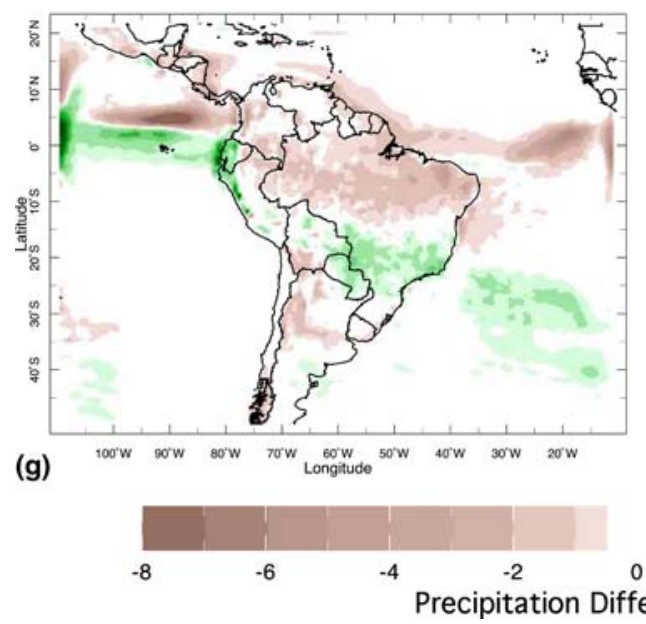

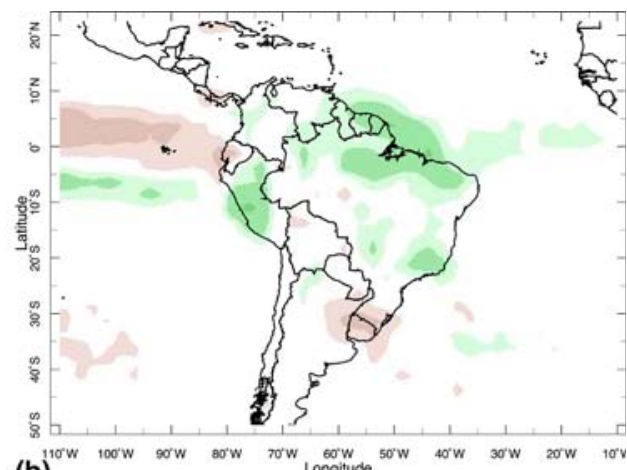

(b)

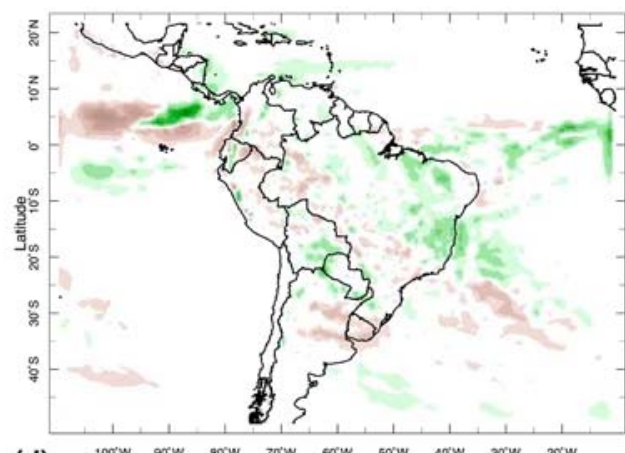

(d)

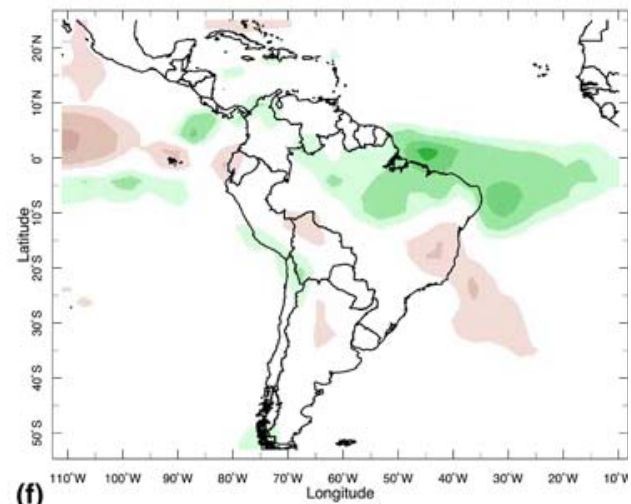

(f)

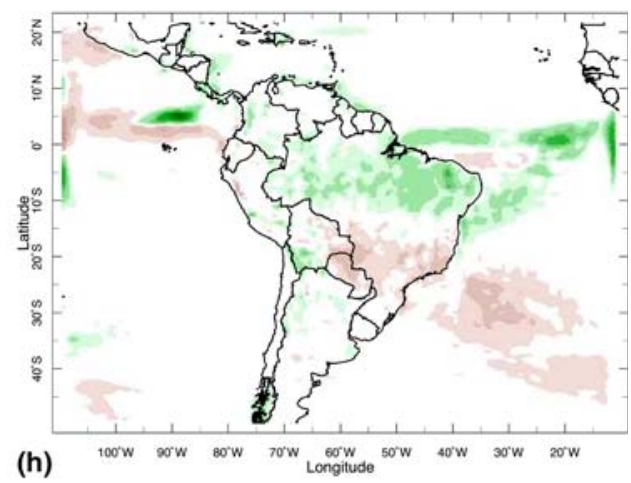

(h)

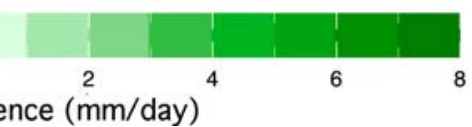


Fig. 8 Composite JFM SLP anomalies for Warm ENSO (1983, 1987, 1992, 1998) (left) and Cold ENSO (1985, 1989, 1999, 2000) (right) from,

a, b NNRP, c, d NN-RegCM, e, f ECHAM, and $\mathbf{g}$,

h EC-RegCM

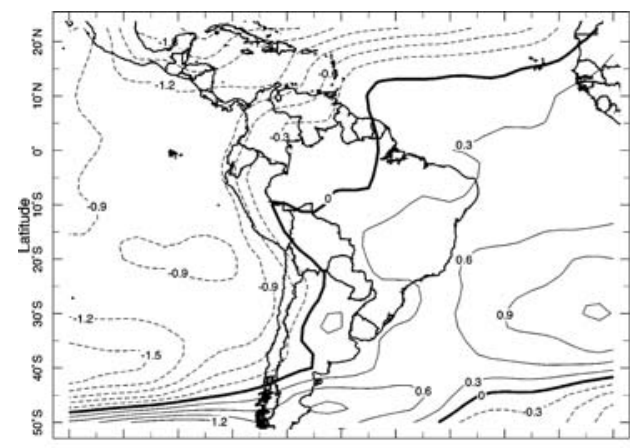

(a)

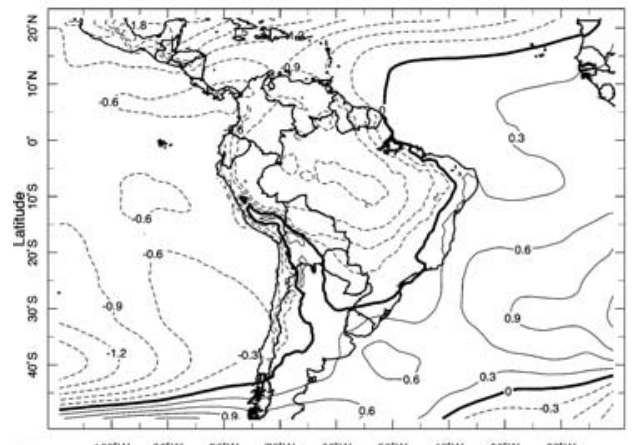

(c)

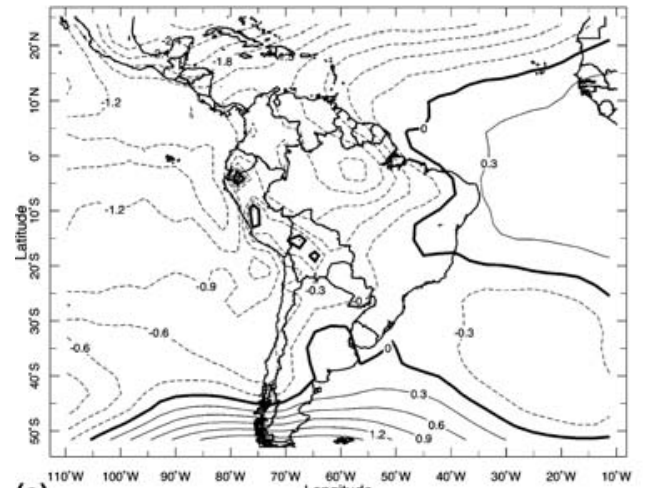

(e)

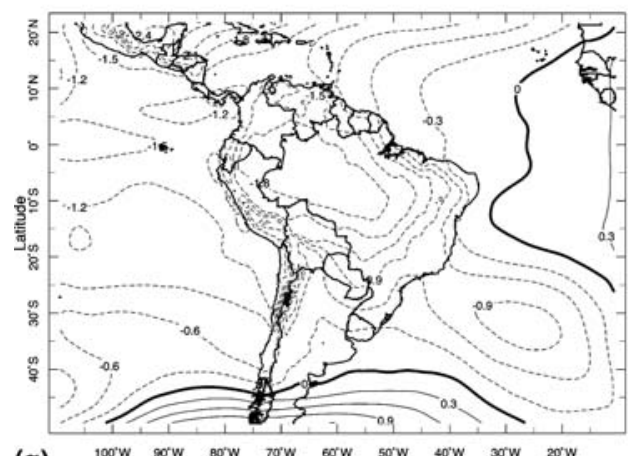

(g)

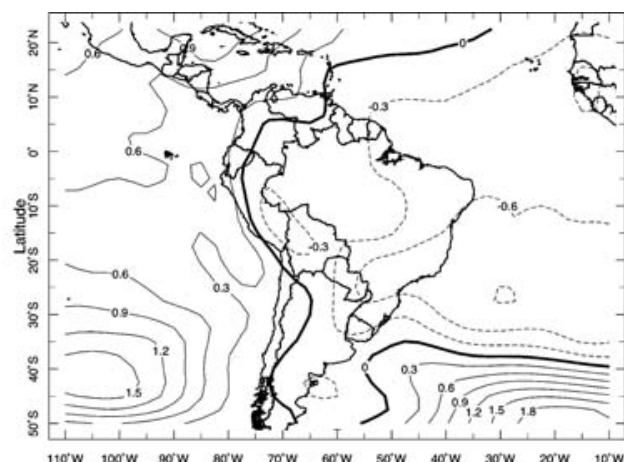

(b)

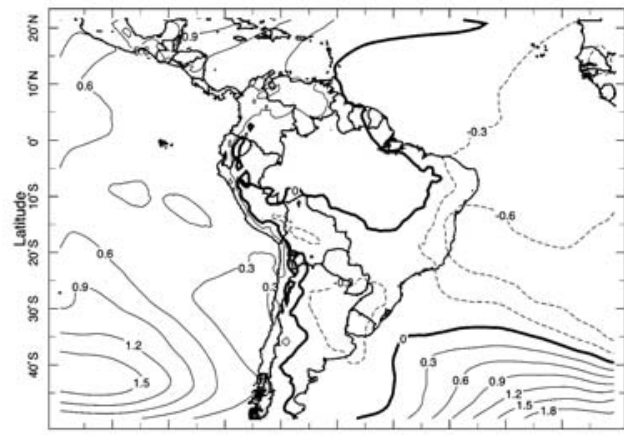

(d)
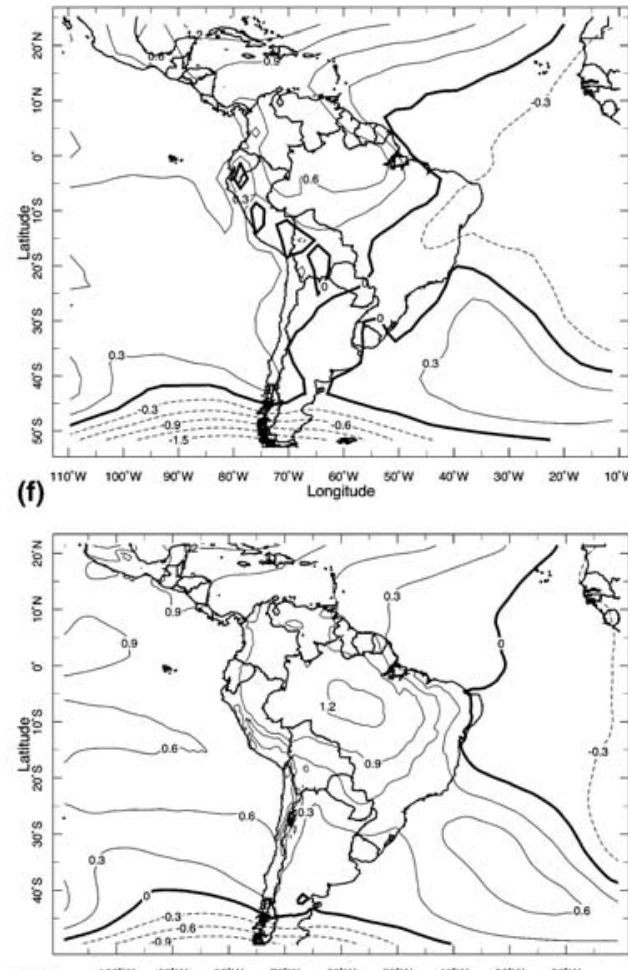

(h) tropical Atlantic. The simulated Walker circulation is disrupted, and the ascending branch is displaced eastward to the area of the Atlantic ITCZ. Thus the interannual variation over North Amazon becomes in phase with tropical Pacific instead of tropical Atlantic.
Indeed, the correlation between Amazon region precipitation anomaly and eastern tropical Pacific SST anomaly is positive (not shown).

Despite errors in the simulation of the annual cycle in the Amazon basin, the NN-RegCM is capturing the 
interannual variability through much of South American continental monsoon region. In the next section, we focus on the question of predictability by examining the GCM and GCM driven RegCM3 results.

\subsection{GCM driven RegCM}

\subsubsection{Mean annual cycle}

The ECHAM global model ensemble simulates the annual cycle of precipitation over South America well (Fig. 2c). There is some indication of a southward initiation of rains near $10^{\circ} \mathrm{S}$ similar to observed, however, the maximum $(6 \mathrm{~mm} /$ day $)$ rainfall extends farther south $\left(28^{\circ} \mathrm{S}\right)$ than CMAP $\left(20^{\circ} \mathrm{S}\right)$. The quality of the ECHAM model annual cycle is seen also in the area averages for the Northeast, Southeast, Amazon and Monsoon (Fig. 3a-d). In the Northeast the GCM simulates the amplitude of the annual cycle very well, but the phase is shifted to be early. Rauscher et al. (2006) show this result in more detail when examining simulated rainfall onset from these simulations. In the Southeast the GCM captures the small amplitude annual cycle but exhibits a slight dry bias. In the northern Amazon, while there is some tendency for a semi-annual cycle in the global model, it simulates both the amplitude and the phase better than the regional model in this region. In the Monsoon region, the global model simulates the large amplitude annual cycle, but shows early onset and late demise of the rains. Figure $4 \mathrm{e}, \mathrm{f}$ also shows that the ECHAM model simulates the continental scale spatial pattern of monsoon precipitation and its retreat.

The EC-RegCM (Fig. 2d) is also dry in the Amazon as in the NN-RegCM, and the southward displacement of the maximum precipitation is also similar in all RegCM integrations. Figure $3 a-d$ shows clearly that the simulated annual cycles in all of the regions are very similar using both reanalysis and GCM driving fields, although small differences do exist. For example, in the Northeast the NN-RegCM simulates a better amplitude in peak precipitation. In Fig. $4 \mathrm{~g}$, h we can see that the precipitation patterns are indeed very similar for the reanalysis and GCM driven regional simulations. The differences between the regional model simulations (Fig. 4g, h vs. Fig. 4c, d) are in the SACZ and ITCZ regions; the NN-RegCM shows stronger precipitation in the SACZ during JFM and the EC-RegCM shows a tilt in the ITCZ towards the northeast. These differences occur where the lateral boundary forcing have a more pronounced effect. Recall that there is no direct forcing in the interior of the domain, the large scale forcing is applied in a buffer region along the lateral boundaries of the domain.

\subsubsection{Interannual variability}

The response of the ECHAM model to ENSO forcing is quite strong, in part due to the enhanced signal resulting from the ensemble. The ECHAM simulations (Fig. 5e, f) capture the observed relationships very well in the Northeast, where both Pacific and Atlantic anomalies contribute to the variability of rainfall. In the Southeast the relationship to Pacific SST is stronger than observed. When driven by the ECHAM model, the relationship of EC-RegCM Southeast rainfall to tropical Pacific SST weakens (Fig. 5h) relative to the NN-RegCM.

The ability of ECHAM and EC-RegCM to reproduce observed seasonal precipitation anomalies is shown in Fig. 6 (and correlations in Table 2) for the Northeast, Southeast and Amazon regions. In the Northeast (Fig. 6a) the models all simulate the sign of the FMA anomalies well, and the ECHAM model (correlation $=0.83$ ) captures the peak amplitudes of the dry events in 1993 and 1998 and the wet event in 1985 better than the regional model (correlation $=0.60)$. In the Southeast (Fig. 6b) in OND, the ECHAM variability is weaker than observed (correlation $=0.55)$ and the EC-RegCM (correlation =0.30) follows the lead of the global model, with even smaller amplitude variation, e.g. the wet event in 1998 is very weak in the GCM driven regional model. The GCM simulates the anomalies in the Amazon basin in DJF very well (correlation $=0.89$ ) and the $\mathrm{EC}-\mathrm{RegCM}$ (correlation $=0.79$ ), again, follows the GCM, but shows reduced amplitude anomaly in 1989 (Fig. 6c). Note in the Amazon, the EC-RegCM is much improved over the NN-RegCM! The enhanced precipitation in GCM, particularly in December (Fig. 3c), induces stronger than observed northeasterly trade winds from the Atlantic, which compensates the bias of RegCM in underestimation the wind speed of the trades. Interannual variability is poorlysimulated in the Monsoon region by the global model (correlation $=0.07$ ), while the regional model does improve upon this (correlation $=0.22$ ).

In the warm and cold event composites of precipitation shown in Fig. 7, we see that the ECHAM model (Fig. 7e, f) and the EC-RegCM (Fig. 7g, h) are simulating the correct anomalies in the Northeast and Amazon, although the SLP anomalies in the Amazon seem to be related more to the Pacific than the Atlantic (Fig. 8). In the Southeast, CMAP estimates describe a 
wet anomaly during the warm events and a weak dry anomaly during cold events, however the GCM simulates weak anomalies over northern Argentina and also southeastern Brazil of the same signs. In response to the GCM forcing the EC-RegCM simulates a wet (dry) anomaly during the warm (cold) events in the SACZ and through southeastern Brazil. The SLP composites illustrate that the EC-RegCM (Fig. 8g, h) follows the lead of the GCM (Fig. 8e, f) in simulating SLP anomalies in the subtropical South Atlantic.

Figure 8 demonstrates the control of the lateral boundary forcing. The NN-RegCM SLP anomaly patterns closely follow those of NNRP and likewise, the EC-RegCM SLP anomaly follows that of the ECHAM driving fields. It was noted earlier that the NN-RegCM showed the opposite of the observed anomaly in the interior Amazon. Interestingly, all of the model simulations show this response. It is not clear why this is so, but the mechanisms for this response may be different between the GCM and the RegCM, as they employ different land surface boundary layer and convective parameterizations.

\section{Discussion}

Our results indicate that there is value in examining the regional climate model nested in two unique sources of boundary forcing, in this case reanalysis and multiple realizations of a GCM. The evaluation of the annual cycle reveals a bias in the northern Amazon region which appears in the nested model regardless of the choice of boundary forcing (Figs. 2, 3). The similarity of the Amazon annual cycle in the NN-RegCM and EC-RegCM integrations suggests the source of this bias is in the regional model. While the dry bias was noted in earlier seasonal simulations (Seth and Rojas 2003; Rojas and Seth 2003) there was no prior information related to the annual cycle. In the present results we see that the regional model simulates a semiannual cycle and underestimates precipitation in all months except September-November, the early rainy season. The semi-annual cycle is a problem in numerous models (Bonan et al. 2002; Marengo et al. 2003; M. Rojas et al. in preparation). The GCM employed in this study is one of the few that are able to simulate an annual cycle within reason of the observed.

While the different driving fields (GCM and reanalysis) appear to have small influence on the regional model's climatological annual cycle, they do influence the interannual variability simulated by the RegCM. In the four sub-regions studied, the RegCM simulated year-to-year variations in precipitation tend to follow more closely that of the driving fields (Fig. 6). The SLP composites show that the ECHAM model does not capture the observed ENSO related signal in the subtropical South Atlantic, i.e. an equatorward (poleward) shift of the subtropical high during warm (cold) events (Fig. 8). The NN-RegCM simulation of interannual variability in the southeast is much better than both the GCM and EC-RegCM (Fig. 5, 6) with a correlation of 0.78 compared to 0.55 and 0.3 , respectively (Table 2). Only in the Monsoon region the RegCM outperform the GCM with both sets of driving fields, thus adding value to the GCM, It is in this region where large scale teleconnections from remote SST anomalies are weak, and thus local physical processes may have more influence. The regional model is able to capture some of these processes, but correlations between observed and simulated precipitation are generally weak ( 0.25 at best).

We have also noticed that Amazon region NNRegCM precipitation appears to increase in the later part of the simulation period. Annual precipitation, and root layer soil moisture are given for the Amazon in Fig. 9 ( $a$ and b, respectively). An increase is apparent in both the observed estimate (CMAP) and the NN-RegCM integration since the mid-1990s. This increase in precipitation occurs in the reanalysis driven simulation and is not seen in either the EC-RegCM or in the ECHAM model. It can also be seen that the root layer moisture adjusts dramatically to the precipitation simulation during the first simulation year (which includes the 1982-1983 El Niño) in both EC-RegCM and NN-RegCM. But only NN-RegCM follows the precipitation increase later in the simulation. Thus, it appears to be related to the same conditions that lead to the increase in observed precipitation and is not related to soil moisture recovery after initialization. It must be noted that this recent increase in JFM Amazon precipitation is not consistent with any published trends. Marengo (2004) have suggested a long-term drying trend in this region based on gauge precipitation using October-April measurements.

\subsection{MIT convection scheme}

The problems in the Amazon simulation do not appear to be caused by land surface feedback. As we have seen the land is responding to the precipitation conditions and does not appear to be a primary forcing of the bias. We have also noted deficiencies in the large scale circulation, i.e. the SLP is high in the equatorial Atlantic, which reduces the strength of the trade winds, and resulting moisture transport into the continent. The ECHAM model has much stronger moisture 
Fig. 9 1982-2003 annual mean a precipitation $(\mathrm{mm} /$ day) and b root layer soil moisture $(\mathrm{mm})$ from CMAP (soild-thick), ECHAM (solidthin), NN-RegCM (dashedthick), and EC-RegCM (dashed-thin) for the Amazon region
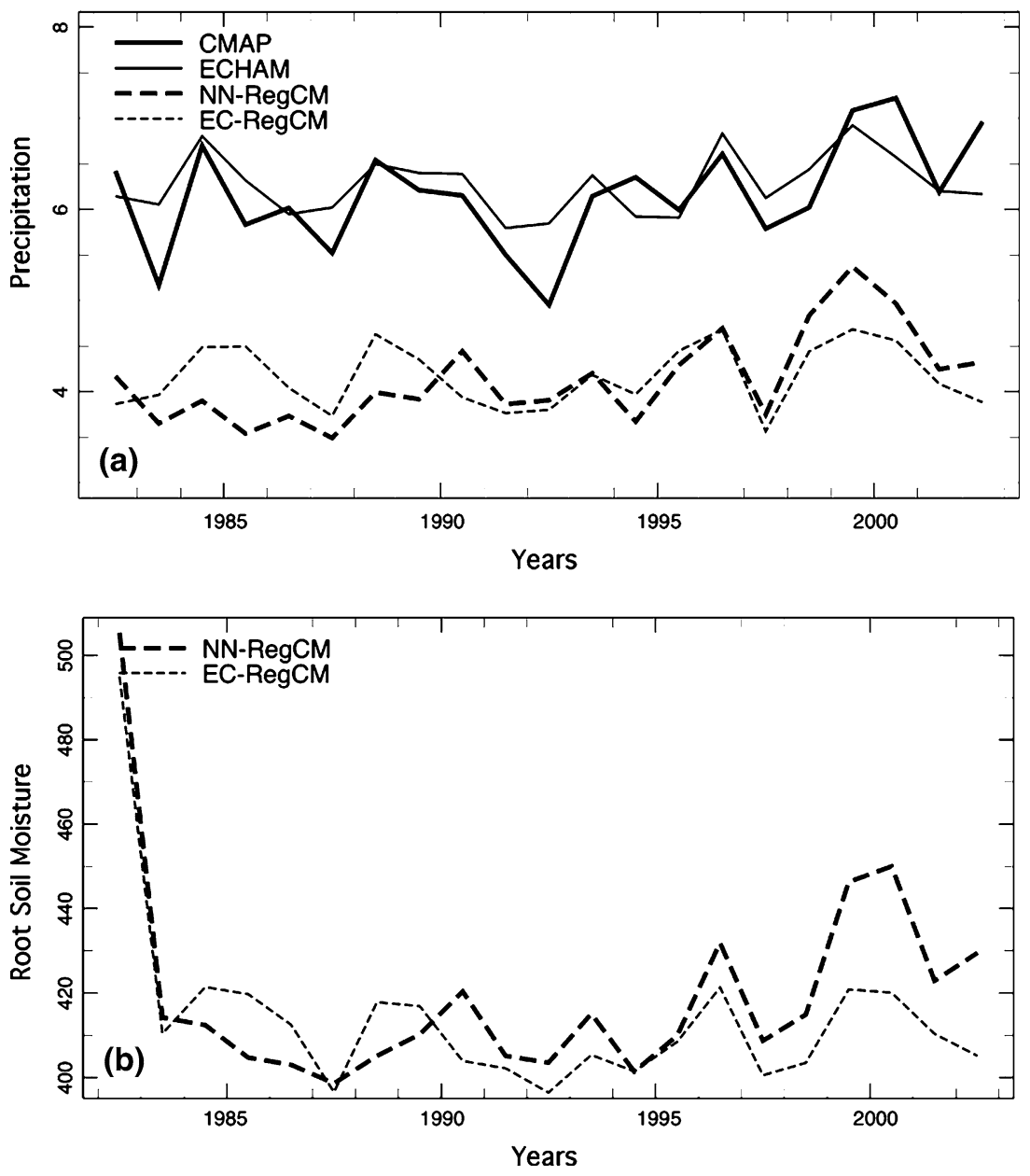

transport, similar to the reanalysis, than the regional model (not shown). The convection scheme employed in RegCM (Grell et al. 1994) has been employed for many studies and performs quite well in mid-latitudes (Giorgi et al. 1994, 2004; Mearns et al. 1995; Pal et al. 2000). However, over tropical continents weaker than observed circulation has been noted (Seth and Rojas 2003; Afiesimama et al. 2006) and much testing of the physical parameters in the scheme has been performed to understand and improve this weakness. Further development of RegCM3 for improved simulation in the tropics has involved the implementation of the MIT convection scheme (Emanuel 1991). We have performed a set of 7-year integrations (1996-2002) which employ both reanalysis and three realizations of the ECHAM model boundary forcing.

Figure 10 describes the pentad precipitation annual cycle Hovmoeller diagram (similar to Fig. 2) but for the shorter period of simulation, 1996-2002, for CMAP, ECHAM, EC-RegCM and EC-RegCM-EM. The implementation of the Emanuel scheme improves the simulated precipitation throughout the annual cycle. In Fig. 11, the regional average annual cycles are provided, and we see improvement in the timing and amplitude of precipitation from that of the Grell scheme in both the Northeast and Southeast regions. In the Amazon, the timing is also improved, but the peak amplitudes of precipitation are now higher than the observed estimates. The same is evident in the Monsoon region, where the Emanuel scheme produces a larger peak in the rainy season than CMAP. Finally we see that these changes in the annual cycle are directly related to an increase in the moisture transport and improved Atlantic anti-cyclone, shown in Fig. 12. The NN-RegCM-EM (Fig. 12f) shows much improved SLP in the tropical Atlantic and continental regions, and also substantially increased moisture transport into the continent (Fig. 12e) compared with that from NNRegCM (Fig. 12c). Both features are closer to the observed estimates (Fig. 12a, b).

\section{Conclusions}

In order to enable downscaling of seasonal prediction and climate change scenarios, long-term baseline re- 

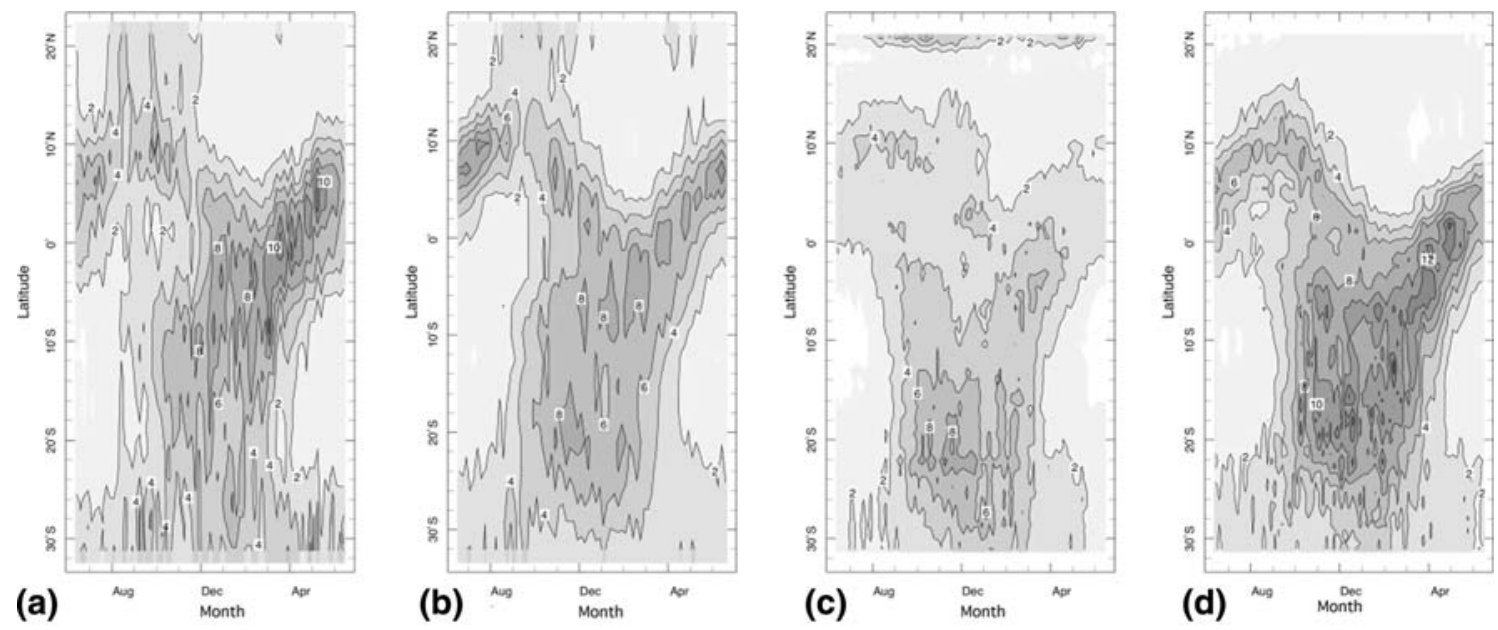

0
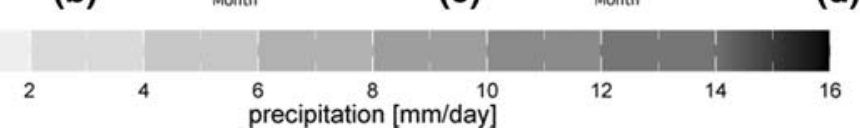

Fig. 10 1996-2003 annual cycle of precipitation shown by latitude and pentad, averaged from $65^{\circ} \mathrm{W}$ to $40^{\circ} \mathrm{W}$ for a CMAP, b ECHAM, c EC-RegCM, and d EC-RegCM-EM
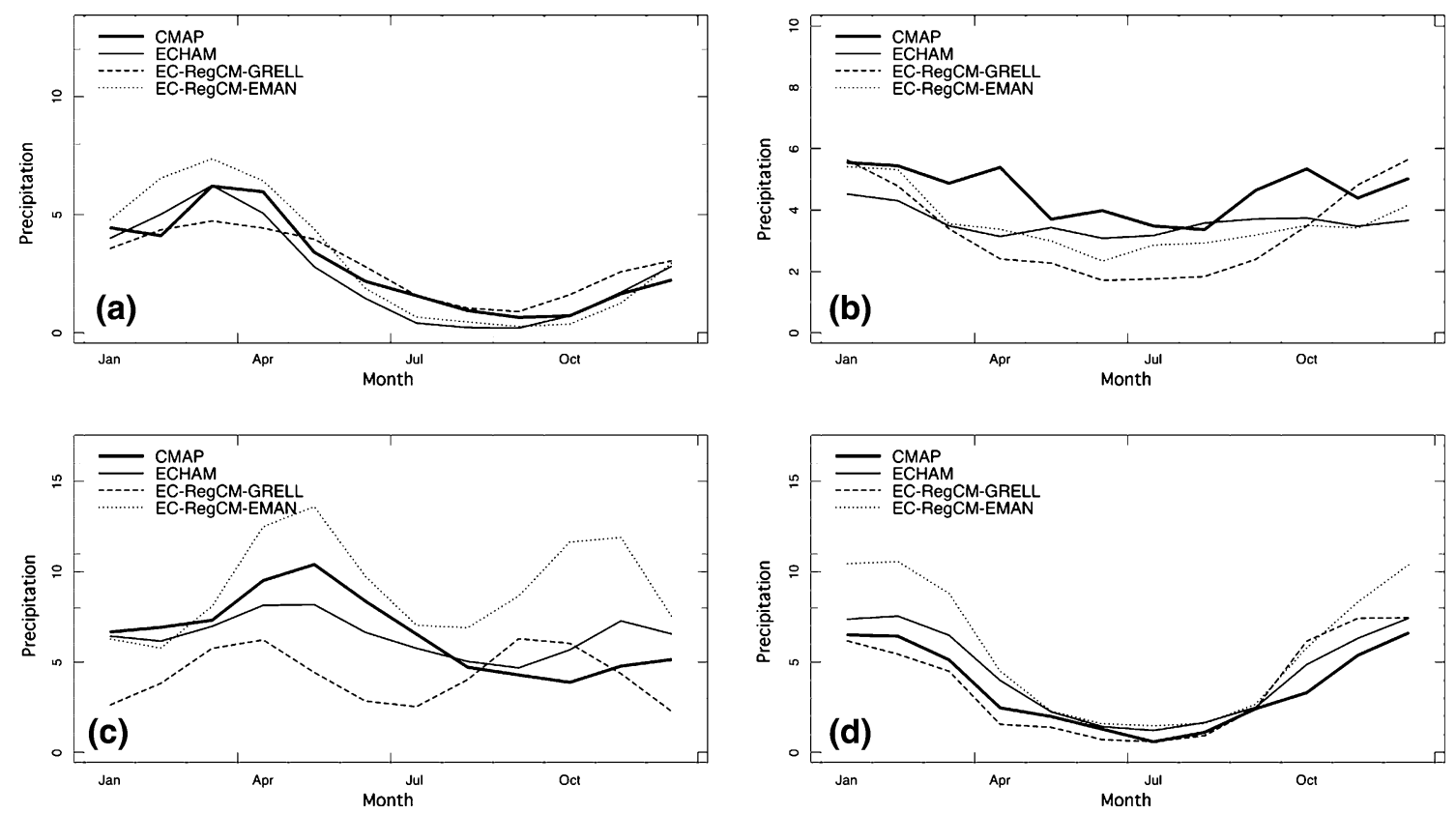

Fig. 11 1996-2003 average monthly precipitation (mm/day) for the a Northeast, b Southeast, c Amazon and d Monsoon regions from CMAP (thick solid), ECHAM (solid), EC-RegCM (dashed), EC-RegCM-EM (dotted) from ECHAM driven simulations

gional climatologies are needed for South America, which employ global model forcing. As a first step in this process, we have set out to examine climatological integrations with a regional climate model using a continental scale domain nested in both reanalysis and multiple realizations of a GCM. Although a number of recent studies have employed regional climate models in this region, many have focused on process studies (Berbery and Collini 2000;
Saulo et al. 2000) and only one (Sun et al. 2006) has performed multi-decade climatology using a small domain focused on Northeast Brazil. As seasonal prediction and climate change scenarios are becoming more viable on regional scales, continental scale evaluation of regional climate models is needed to provide baseline statistics for the evaluation of prediction on seasonal timescales as well as scenarios of future climates. 


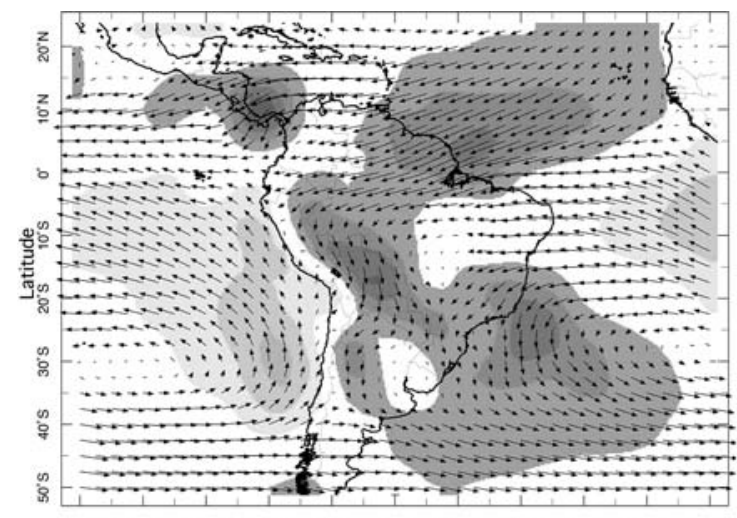

(a)
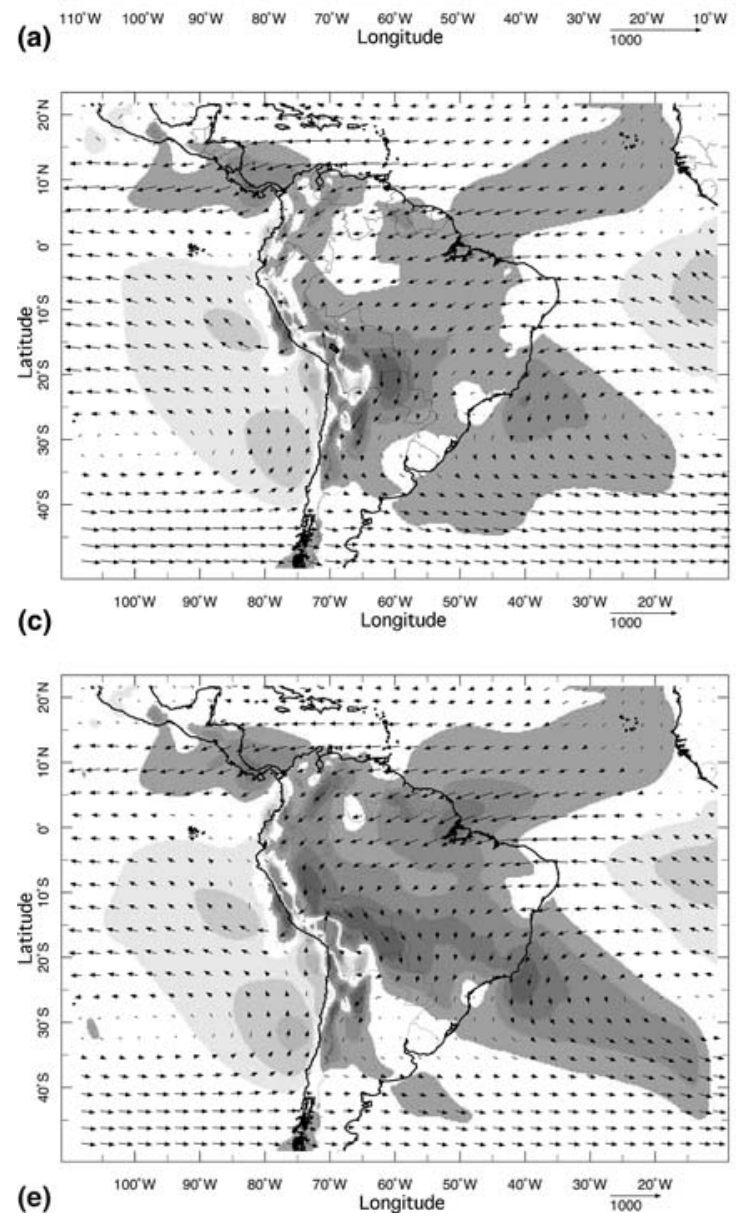

Fig. 12 1996-2003 JFM average vertically integrated moisture transport ( $\mathrm{kg} \mathrm{m} / \mathrm{s}^{2}$, vectors) with meridional component shaded (left) and SLP (hPa) (right) from a, b NNRP, c, d NN-RegCM,

This analysis evaluates the nested model simulated large scale circulation, mean annual cycle and interannual variability which are compared against observational estimates and also with the driving GCM. We have found that the RegCM3 simulates the annual cycle of precipitation well in the Northeast region; it exhibits a small dry bias during winter (JAS) in the Southeast, and simulates a semi-annual cycle with a larger dry bias in summer (DJF) in the Amazon re-

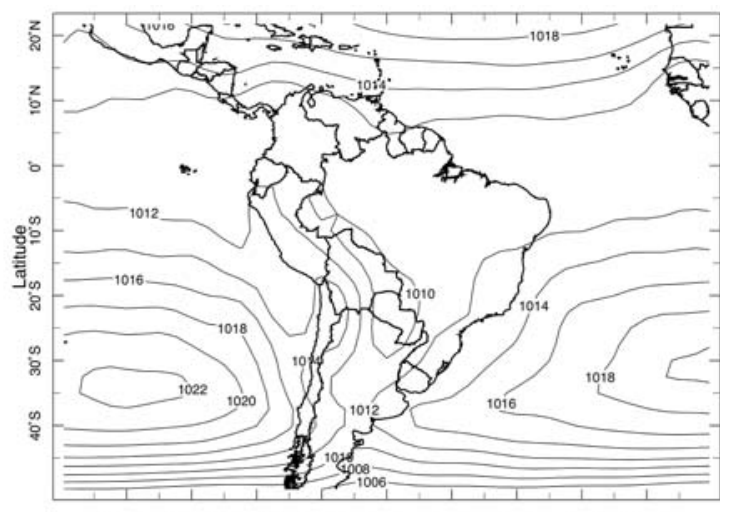

(b)

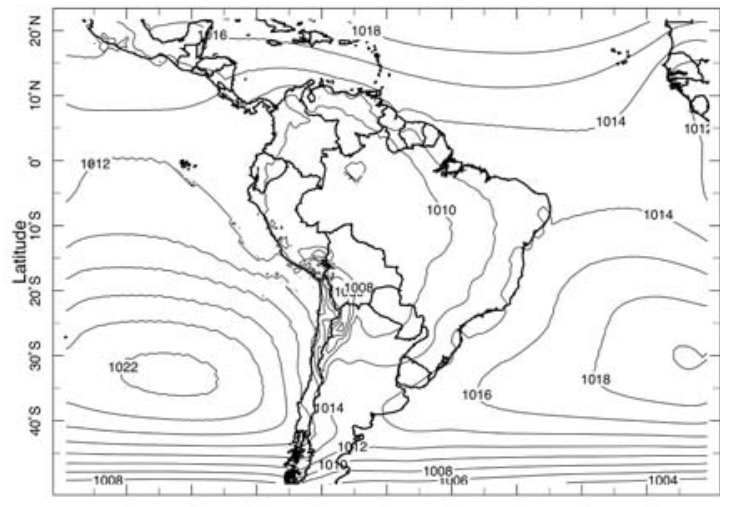

(d)

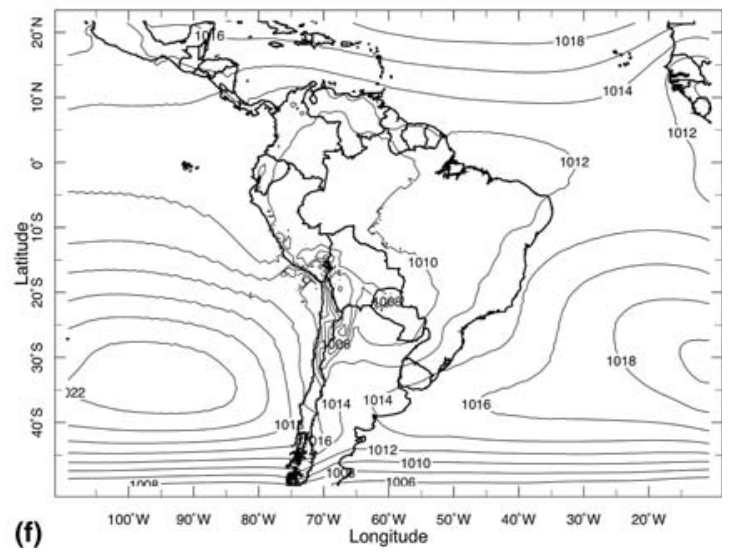

and e, f NN-RegCM-EM. Light (dark) shading begins at 50 (50) $\mathrm{kg} \mathrm{m} / \mathrm{s}^{2}$, with an increment of $50 \mathrm{~kg} \mathrm{~m} / \mathrm{s}^{2}$

gion. The errors in the simulated annual cycle are related to the RegCM3 physical parameterizations. This conclusion is drawn from results which show the regional model annual cycles are very similar regardless of lateral boundary forcing. It is further supported by the substantial changes with some improvement seen in the annual cycle with the implementation of the MIT convection scheme in all four regions analyzed. 
While the annual cycle appears to be largely determined by the regional model, the interannual variability appears to be significantly influenced by differences in applied boundary conditions. Despite the errors in the annual cycle, the RegCM3 captures much of the interannual variability observed in the Northeast, Southeast and Amazon regions. In the Southeast the reanalysis driven RegCM3 (NN-Reg$\mathrm{CM}$ ) performs better than the GCM or GCM driven RegCM3, indicating that the poor simulation of interannual variability in the Southeast region from ECRegCM results from the quality of the GCM boundary conditions. In the Monsoon region, where local physical processes may have more influence on variability (Grimm 2003), the RegCM3 improves upon the GCM simulation, but predictability remains weak.

From these results we conclude that, where large scale SST forced variability is strong and the global model performs well it is difficult for the regional model to improve the large scale climatology, and errors in the regional model may degrade the simulation. Where the global model performs less well and in regions where local physical processes are of importance, regional model does show some potential to improve upon the GCM (e.g. the Monsoon region). In addition, experiments using the MIT convection scheme demonstrate that the model physics have dramatic impact on the large scale circulation and moisture flows which are important to enable local processes. Thus the dominance of physical processes will require improvements in physics (land surface, boundary layer, convection and clouds) before substantial gains can be expected and will be essential to the use of regional models in tropical areas.

The results presented here show that improved model resolution alone is insufficient to provide a quality simulation of South American climate. Further, these results suggest that improvements in physical parameterizations will provide keys to improving simulations of tropical climate, in both regional and global models. It follows that such improvements should be developed for spatial scales that can represent the processes more fully, i.e. high resolution models. Spectral nudging of large scales has been examined for mid-latitude domains, but has not yet been explored in an equatorial domain. Those who have examined nudging in mid-latitudes find it improves circulation errors, but often worsens errors in the sub-grid physics (i.e. precipitation) (von Storch et al. 2000; MiguezMacho et al. 2004; Castro et al. 2005). In the tropics, where physical processes dominate, it is likely that addressing the source of errors (land surface, boundary layer, convection and clouds) will have more efficacy than placing additional constraints on large scale forcing. This is speculation, and some testing of nudging methods in the tropics is needed.

Finally, having analyzed for South America this long-term nested regional climate model climatology for large scale features and interannual variability, we focus our attention on the higher spatial and temporal frequency data which are needed for applications. A companion paper (S. Rauscher et al. in revision) presents the details of the analysis of the higher order statistics from these simulations.

Acknowledgments The authors thank Filippo Giorgi for the use of RegCM3 and Dave Dewitt for assistance with the ECHAM global model. Dr. Xunqiang Bi provided guidance with the model pre- and post-processing. Huilan Li helped to develop the interface between ECHAM and RegCM3. The comments from three anonymous reviewers improved the quality and presentation of these results and are much appreciated. This research was funded in part by NOAA, Award \# NA16GP2029, and the International Research Institute for Climate and Society \# NA050AR4311004. The views expressed herein are those of the author(s) and do not necessarily reflect the views of NOAA or any of its sub-agencies.

\section{References}

Afiesimama EA, Pal JS, Abiodun BJ, Gutowski WJ, Adedoyin A (2006) Simulation of West African monsoon using the RegCM3. Part I: Model validation and interannual variability. Theor Appl Cimatol. DOI:10.1007/s00704-005-02028

Arakawa A (1993) Closure assumptions in the cumulus parameterization problem, vol. The representation of cumulus convection in numerical models. American Meteorological Society, Boston

Arakawa A, Schubert WA (1974) Interaction of a cumulus cloud ensemble with the large scale environment, Part I. J Atmos Sci 31:674-701

Barreiro M, Chang P, Saravanan R (2002) Variability of the South Atlantic convergence zone simulated by an atmospheric general circulation model. J Clim 15:745-763

Barros V, Doyle M, González M, Bejarán R, Caffera R (2002) Climate variability over subtropical South America and the South American monsoon system: a review. Meteorologica 27:33-58

Berbery EH, Collini EA (2000) Springtime precipitation and water vapor flux over southeastern South America. Mon Wea Rev 124:2322-2339

Bonan GB, Oleson KW, Vertenstein M, Levis S, Zeng X, Dai Y, Dickinson RE, Yang ZL (2002) The land surface climatology of the community land model coupled to the NCAR community climate model. J Clim 15:3123-3149

Carvalho LMV, Jones C, Liebmann B (2004) The South Atlantic convergence zone: intensity, form, persistence, and relationships with intraseasonal to interannual activity and extreme rainfall. J Clim 17:88-108

Castro C, Pielke Sr RA, Leoncini G (2005) Dynamical downscaling: assessment of value retained and added using the Regional Atmospheric Modeling System (RAMS). J Geophys Res 110(D05108). DOI:10.1029/2004JD004721 
Cavalcanti IFA, Marengo JA, Satyamurty P, Nobre CA, Trosnikov I, Bonatti JP, Manzi A, Tarasova T, Pezzi LP, D'Almeida C, Sampaio G, Castro CC, Sanches MB, Camargo H (2002) Global climatological features in a simulation using the CPTEC-COLA AGCM. J Clim 15(21):2965-2988

Chou SC, Tanajura CAS, Xue Y, Nobre CA (2002) Validation of the coupled Eta/SSiB model over South America. J Geophys Res 107, d20, 8088. DOI:10.1029/2000JD000270

Christensen OB, Christensen JH, Machenhauer B, Botzet M (1998) Very high resolution regional climate simulations over Scandanavia: present climate. J Clim 11:3204-3229

Christensen JH, Carter TR, Giorgi F (2002) PRUDENCE employs new methods to assess European climate change. EOS Trans 83:147

Cook KH, Vizy EK (2005) South American climate during the last glacial maximum: delayed onset of the South American monsoon. J Geophys Res 111, d02110

Dickinson RE, Henderson-Sellers A, Kennedy PJ (1993) Biosphere-atmosphere transfer scheme (BATS) version 1e as coupled to the NCAR community climate model. Tech Note TN-387+STR, NCAR, pp 72

Eltahir EAB, Bras RL (1993) On the response of the tropical atmosphere to large-scale deforestation. Quart J R Meteor Soc 119:779-793

Eltahir EAB, Bras RL (1994) Sensitivity of regional climate to deforestation in the Amazonbasin. Adv Water Res 17:101115

Emanuel KA (1991) A scheme for representing cumulus convection in large-scale models. J Atmos Sci 48(21):23132335

Emanuel KA, Zivkovic-Rothman M (1999) Development and evaluation of a convection scheme for use in climate models. J Atmos Sci 56:1766-1782

Fu C (2003) Potential impacts of human induced land cover change on East Asia monsoon. Glob Planet Change 37:219 229

Giorgi F, Shields C, Bates GT (1994) Regional climate change scenarios over the United States produced with a nested regional climate model. J Clim 7:375-399

Giorgi F, Bi X, Pal JS (2004) Mean, interannual variability and trends in a regional climate change experiment over Europe. I. Present day climate (1961-1990). Clim Dyn 22:733-756

Grell G, Dudhia J, Stauffer D (1994) A description of the fifth generation Penn State NCAR Mesoscale Model (MM5). Technical report NCAR, 398

Grimm AM (2003) El Nino impact on the summer monsoon in Brazil: regional processes versus remote influences. J Clim 16:263-280

Hastenrath S, Heller L (1977) Dynamics of climatic hazards in northeast Brazil. Quart J R Meteor Soc 435:77-92

Holtslag AAM, Boville BA (1993) Local versus nonlocal boundary layer diffusion in a global climate model. J Clim 6:1825-1842

Huntingford C, Gash J (2005) Climate equity for all. Science 309:1789

Indeje M, Semazzi FHM, Xie L (2001) Mechanistic model simulations of the East African climate using NCAR regional climate model: influence of large scale orography on the Turkana low-level jet. J Clim 14:2710-2724

Kalnay E, Kanamitsu M, Kistler R, Collins W, Deaven D, Gandin L, Iredell M, Saha S, White G, Woollen J, Zhu Y, Leetmaa A, Reynolds B, Chelliah M, Ebisuzaki W, Higgins W, Janowiak J, Mo KC, Ropelewski C, Wang J, Jenne R, Joseph D (1996) The NCEP/NCAR 40-year reanalysis project. Bull Am Meteor Soc 77:437-472
Kiehl JT, Hack JJ, Bonan GB, Boville BA, Williamson DL, Rasch PJ (1998) The National Center for Atmospheric Research Community Climate Model (CCM3). J Clim 11:1307-1326

Kousky VE (1988) Pentad outgoing longwave radiation climatology for the South American sector. Rev Bras Meteor 3:217-231

Leung LR, Qian Y, Bian X, Washington WM, Han J, Roads JO (2004) Mid-century ensemble regional climate change scenarios for the western United States. Clim Change 62:75113

Marengo JA (2004) Interdecadal variability and trends of rainfall across the Amazon basin. Theor Appl Climatol 78:79-96

Marengo JA, Cavalcanti IFA, Satyamurty P, Trosnikov I, Nobre CA, Bonati JP, Camargo H, Sampaio G, Sanches MB, Manzi AO, Castro CAC, D'Almeida C, Pezzi LP, Candido L (2003) Assessment of regional seasonal rainfall predictability using the CPTEC/COLA atmospheric GCM. Clim Dyn 21:459-475

McGregor JL, Walsh K (1994) Climate change simulations of Tasmanian precipitation using multiple nesting. J Geophys Res 99:20889-20905

Mearns LO et al (2005) North American regional climate change assessment program. In: Proceedings of the 85th American Meterological Society Annual Meeting, san Diego

Mearns L, Giorgi F, McDaniel L, Shields C (1995) Analysis of daily precipitation variability in a nested regional climate model: comparison with observations and $2 \times \mathrm{CO}_{2}$ results. Glob Planet Change 10:55-78

Menéndez CG, Cabré MF, Nuñez MN (2004) Interannual and diurnal variability of January precipitation over subtropical South America simulated by a regional climate model. CLIVAR Exchanges

Miguez-Macho G, Stenchikov GL, Robock A (2004) Spectral nudging to eliminate the effects of domain position and geometry in regional climate model simulatons. J Geophys Res 109(D13104). DOI:10.1029/2003JD004495

Moura AD, Shukla J (1981) On the dynamics of droughts in Northeast Brazil: observations, theory and numerical experiments with a general circulation model. J Atmos Sci 38:2653-2675

Nobre P, Moura AD, Sun L (2001) Dynamical downscaling of seasonal climate prediction over Nordeste Brazil with ECHAM3 and NCEP's regional spectral model at IRI. Bull Am Meteor Soc 82:2787-2796

Nogués-Paegle J, Mo KC (1997) Alternating wet and dry conditions over South America during summer. Mon Wea Rev 125:279-291

Pal JS, Small EE, Eltahir EAB (2000) Simulation of regionalscale water and energy budgets: representation of subgrid cloud and precipitation processes within RegCM. J Geophys Res 105(D24):29579-29594. DOI:10.1029/2000JD900415

Pal J, Giorgi F, Bi X (2004) Consistency of recent European summer precipitation trends and extremes with future regional climate projections. Geophys Res Let 31(L13202). DOI:10.1029/2004GL019836

Pal JS, Giorgi F, Bi X et al (2006) The ICTP RegCM3 and RegCNET: regional climate modeling for the developing World. Bull Am Meteorol Soc (in press)

Qian JH, Tao WK, Lau KM (2004) Mechanisms for torrential rain associated with the Mei-yu development during SCSMEX 1998. Mon Wea Rev 132:3-27

Rauscher SA, Seth A, Qian JH, Camargo SJ (2006) Domain choice in an experimental nested modeling prediction system for South America. Theor App Climatol. DOI:10.1007/s00704-006-0206-Z 
Reynolds RW, Rayner NA, Smith TM, Stokes DC, Wang W (2002) An improved in situ and satellite SST analysis for climate. J Clim 15:1609-1625

Robertson AW, Mechoso CR (2000) Interannual and interdecadal variability of the south Atlantic convergence zone. Mon Wea Rev 128:2947-2957

Roeckner E, Arpe K, Bengtsson L et al (1996) The atmospheric general circulation model ECHAM-4: model description and simulation of present day climate. Technical Report 218, Max-Planck Institute for Meteorology

Rojas M, Seth A (2003) Simulation and sensitivity in a nested modeling system for South America. Part II: GCM boundary forcing. J Clim 16:2454-2471

Ropelewski CF, Halpert MS (1987) Global and regional scale precipitation patterns associated with the El Niño Southern Oscillation. Mon Wea Rev 115:1606-1626

Saulo AC, Nicolini M, Chou SC (2000) Model characterization of the South American low level flow during the 1997-1998 spring-summer season. Clim Dyn 16:867-881

Seth A, Rojas M (2003) Simulation and sensitivity in a nested modeling system for South America. Part I: Reanalyses boundary forcing. J Clim 16:2437-2453

von Storch H, Lanenberg H, Feser F (2000) A spectral nudging technique for dynamical downscaling purposes. Mon Wea Rev 128:3664-3673

Sun L, Moncunill DF, Li H, Moura AD, Filho FAS (2005) Climate downscaling over Nordeste, Brazil, using the NCEP RSM97. J Clim 18:551-567
Sun L, Moncunill DF, Li H, Moura AD, de Assis F, Zebiak SE (2006) An operational dynamical downscaling prediction system from Nordeste Brazil and the 2002-04 real-time forecast evaluation. J Clim 19:1990-2007

Tiedtke M (1989) A comprehensive mass flux scheme for cumulus parameterization on large scale models. Mon Wea Rev 117:779-1800

Vera CS, Vigliarolo PK, Berbery EH (2002) Cold season synoptic-scale waves over subtropical South America. Mon Wea Rev 130:684-699

Vizy EK, Cook KH (2005) Evaluation of LGM SST reconstructions throug their influence on South American climate. J Geophys Res 110(D11105). DOI:10.1029/2004JD005415

Wang Y, Leung LR, McGregor JL, Lee DK, Wang WC, Ding Y, Kimura F (2004) Regional climate modeling: progress, challenges, and prospects. J Meteor Soc Jpn 82(6):1599-1628

Xie P, Arkin P (1996) Analysis of global monthly precipitation using gauge observation, satellite estimates and numerical model predictions. J Clim 9:840-858

Zeng X, Zhao M, Dickinson RE (1998) Intercomparison of bulk aerodynamic algorithms for the computation of sea surface fluxes using TOGA COARE and TAO data. J Clim 11:2628-2644 